NBER WORKING PAPER SERIES

\title{
FACTOR HOARDING AND THE PROPAGATION OF BUSINESS CYCLE SHOCKS
}

Craig Burnside

Martin Eichenbaum

Working Paper No. 4675

\section{NATIONAL BUREAU OF ECONOMIC RESEARCH 1050 Massachusetts Avenue Cambridge, MA 02138 March 1994}

We thank Lawrence Christiano, Jonas Fisher, Lars Hansen, Michael Parkin, and seminar participants at the Federal Reserve Bank of Richmond, the London School of Economics, the University of Chicago, the University of Pittsburgh, the University of Pompeu Fabra, and the University of Western Ontario for their helpful comments and suggestions. This paper is part of NBER's research program in Economic Fluctuations. Any opinions expressed are those of the authors and not those of the National Bureau of Economic Research. 


\title{
FACTOR HOARDING AND THE PROPAGATION OF BUSINESS \\ CYCLE SHOCKS
}

\begin{abstract}
This paper analyzes the role of variable capital utilization rates in propagating shocks over the business cycle. To this end we formulate and estimate an equilibrium business cycle model in which cyclical capital utilization rates are viewed as a form of factor hoarding. We find that variable capital utilization rates substantially magnify and propagate the impact of shocks to agents' environments. The strength of these propagation effects is evident in the dynamic response functions of various economy wide aggregates to shocks in agents' environments, in the statistics that we construct to summarize the strength of the propagation mechanisms in the model and in the volatility of exogenous technology shocks needed to explain the observed variability in aggregate U.S. output. Other authors have argued that standard Real Business Cycle (RBC) models fail to account for certain features of the data because they do not embody quantitatively important propagation mechanisms. These features include the observed positive serial correlation in the growth rate of output, the shape of the spectrum of the growth rate of real output and the correlation between the forecastable component of real output and various other economic aggregates. Allowing for variable capital utilization rates substantially improves the ability of the model to account for these features of the data.
\end{abstract}

Craig Burnside Department of Economics University of Pittsburgh Pittsburgh, PA 15203
Martin Eichenbaum Department of Economics Northwestem University Evanston, IL 60208 and NBER 


\section{Introduction}

This paper analyzes the role of variable capital utilization rates in propagating shocks over the business cycle. To this end we formulate and estimate an equilibrium business cycle model in which cyclical capital utilization rates are viewed as a form of factor hoarding. ${ }^{1}$ We find that variable capital utilization rates substantially magnify and propagate the impact of shocks to agents' environments. The strength of these propagation effects is evident in the dynamic response functions of various economy wide aggregates to shocks in agents' environments, in the statistics that we construct to summarize the strength of the propagation mechanisms in the model and in the volatility of exogenous technology shocks needed to explain the observed variability in aggregate U.S. output. Other authors have argued that standard Real Business Cycle (RBC) models fail to account for certain features of the data because they do not embody quantitatively important propagation mechanisms. These features include (i) the observed positive serial correlation in the growth rate of output (Cogley and Nason 1993), (ii) the shape of the spectrum of the growth rate of real output (King and Watson 1993, Watson 1993) and (iii) the correlation between the forecastable component of real output and various other economic aggregates (Rotemberg and Woodford 1994). Allowing for variable capital utilization rates substantially improves the ability of the model to account for these features of the data.

It is well known that standard Real Business Cycle models do no embody quantitatively important propagation mechanisms." As a result, these models must rely on highly variable, exogenous, aggregate technology shocks to account for the observed fluctuations of interpreting movements in the Solow residual as reflecting stochastic movements in the aggregate production technology. But, by now, there is abundant evidence casting doubt on this interpretation. In addition to reviewing this evidence, Cochrane (1994) discusses the difficulty in finding quantitatively large sources of aggregate shocks - monetary or real

\footnotetext{
IOther anthors who have recently stadied the role of different typee of factor hoarding in business cycle fuctuations include Basn (1993), Bilo and Cho (1993), Buratide, Eichenbaum and Rebelo (1993), Cooley, Hansen and Preocott (1993), Finn (1991), Gordon (1990), Greenwood, Hercowit: and Huffman (1988), Greenwood, Hercowite and Krussel (1992), Kydland and Prescott (1988), Rotemberg and Summers (1990), and Sbordone (1993).

${ }^{2}$ See for example Chriatiano (1988), Cogley and Nwon (1993), King and Rebelo (19932), King and Watson (1993), Watson (1993) and Rotemberg and Woodford (1994).
} 
- to the postwar U.S. economy. This serves as our motivation for understanding how the shocks that do occur are magnified and propagated over time. In this paper we pursue one obvious source of propagation - variable capital utilization (as well as labor hoarding) and investigates its quantitative importance in an otherwise standard Real Business Cycle model.

To model variable capital utilization, we assume that the aggregate technology for producing goods depends on effective capital services and effective hours of work. The latter is defined as labor effort times total hours of work. The former is defined as the capital utilization rate times the stock of capital. The rate at which capital depreciates is assumed to be a function of the capital utilization rate. ${ }^{3}$ In equilibrium, frms will, on average, choose to 'hoard' capital, i.e. they will set capital utilization rates to less than capacity. Because of this they can immediately increase the effective stock of capital in response to shocks that raise the marginal product of capital. In the standard model, firms would have to wait at least one period to raise the stock of capital. To the extent that capital takes time to build, they would have to wajt even longer.

We face two key difficulties in empirically implementing our model. The first difficulty is that labor effort is not directly observable and existing measures of capacity utilization are sector specific and subject to substantial measurement error (see Shapiro 1989). However we can exploit the restrictions of our model to measure these variables as functions of other observable variables and certain estimable parameters of the model. The resulting measure of capacity utilization tracks the analog time series published by the Federal Reserve (which covers only the manufacturing sector over the period we study) quite closely. The second difficulty is that, according to our model, technology shocks cannot be measured by the Solow residual. But given our measures of labor effort and capital utilization rates we can purge the Solow residual of the measurement error induced by factor hoarding. The flip side of this calculation is that we can assess the contribution of variable capital utilization rates to the volatility of total factor productivity.

Our main quantitative findings can be summarized as follows. First, capital utilization rates are very volatile relative to the stock of physical capital. Specifically, we estimate

\footnotetext{
${ }^{3}$ This is consintent with the asmomptions made in Greenwood, Hercowits and Huffman (1988), Greenwood, Hercowits and Krussel (1992) and Finn (1991), among others. See Bila and Cho (1993) or Cooley, Haneen and Prescott (1993) for alternative models in which average capital utilisation rates are less than one.
} 
that the standard deviation of the growth rate of effective capital services is roughly 4.5 times higher than the standard deviation of the growth rate of the stock of physical capital. Concentrating on cyclical movements in the stock of capital gives a misleading picture of cyclical movements in effective capital services. Second, we find that allowing for variable capital utilization rates and labor hoarding leads to a roughly $60 \%$ reduction in the estimated variance of the innovation to technology shocks. Most of this reduction is attributable to cyclical movements in the capital utilization rate.

Third, we find that variable capital utilization rates substantially magnify and propagate the impact of shocks to agents' environments. The magnification and propagation effects induced by factor hoarding are sufficiently large that the model does as well as standard RBC models in accounting for the volatility of output. This is true despite the fact that the estimated volatility of technology shocks is much smaller in our model than in the standard RBC model. What distinguishes the models is not whether but how they account for the volatility of output. Virtually all of the output movements in standard RBC models reflect the direct impact of technology shocks on the aggregate production technology. With variable capital utilization rates, only about half of the variance of output is due to the direct impact of technology shocks.

Fourth, we find that our model is able to account for various features of postwar U.S. business cycles that standard RBC modcle wilnot account for. Cogley and Nason (1993) highlight the weak propagation mechanisms in standard RBC models by focusing on the autocorrelation function of the growth rate of output. They show that, to a first approximation, output movements in the model reflect only exogenous technology shocks. So when these shocks are modeled as a random walk, output is very close to being a random walk. This implication is counterfactual: unlike the Solow residual, U.S. output growth is positively serially correlated. With variable capital utilization rates, the model can simultaneously account for the univariate time series properties of the growth rate of output and the Solow residual.

A closely related observation is that standard RBC models do not reproduce the basic shape of the spectrum of post war U.S. output growth (see King and Watson 1993, Watson 1993). According to the standard RBC model, the spectral shape of output growth is the same as the spectral shape of the growth rate of technology shocks. So when the latter are modeled as white noise, the implied spectrum of output growth does not have a peak at 
business cycle frequencies. But with variable utilization rates, the spectrum of the growth rate of output has a significant peak at business cycle frequencies even when the growth rate of technology shocks is white noise.

Rotemberg and Woodford (1994) have highlighted the weak propagation mechanisms in standard RBC models by focusing on the correlation between expected output growth (at various horizons) with objects like the growth rates of output and average productivity, and the logarithms of hours worked and the ratio of consumption to output. One way in which they motivate the importance of these correlations is by connecting the cyclical component of output growth, as defined by Beveridge and Nelson (1981), to its forecastable component. Using the same multivariate time series specification for output, we investigate the performance of our model on the dimensions of the data stressed by Rotemberg and Woodford (1994). Generally speaking, we find that our model does a substantially better job of accounting for these statistics than the standard RBC model. The improvement is particularly marked with respect to the dynamic correlations of the expected growth rate of output (at various horizons) with the current growth rate of output, the expected growth rate of hours worked and the growth rate of average productivity. Even so the model is unable to fully account for the expected growth rate of output or hours worked. This highlights the importance of finding additional sources of shocks to agents' environments and propagation mechanisms for those shocks.

The remainder of this paper is organized as follows. Section 2 displays our model. Section 3 discusses our econometric methodology. Our empirical results are reported in Section 4. Concluding remarks are contained in Section 5.

\section{The Model}

In this section we present a variant of Hansen's (1985) indivisible labor model, modified to incorporate factor hoarding in the form of variable capital utilization rates and varying labor effort. The model economy is populated by a large number of infinitely lived indjviduals. To go to work an individual must incur a fixed cost of $s$ hours. Once at work, an individual stays for a fixed shift length of $f$ hours. The time $t$ instantaneous utility of such a person is given by

$$
\ln \left(C_{t}\right)+\theta \ln \left(T-\varsigma-W_{t} f\right)
$$


Here $T$ denotes the individual's time endowment, $C_{t}$ denotes time $t$ privately purchased consumption, $\theta \geq 0$, and $W_{t}$ denotes the time $t$ level of effort. According to (1) labor suppliers care about effective hours of work. The time $t$ instantaneous utility of a person who does not go to work is given by $\ln \left(C_{t}\right)+\theta \ln (T)$.

Time $t$ output, $Y_{t}$, is produced via the Cobb-Douglas production function

$$
Y_{t}=\left(K_{t} U_{t}\right)^{1-a}\left[N_{t} f W_{t} X_{t}\right]^{a}
$$

where $0<\alpha<1, K_{t}$ denotes the beginning of time $t$ capital stock, $U_{t}$ represents the capital utilization rate, $N_{t}$ denotes the number of individuals at work during time $t$, and $X_{t}$ represents the time $t$ level of technology. According to (2) what matters for output is the total amount of effective capital, $K_{t} U_{t}$, and total effective hours of work, $N_{t} f W_{t}$, used in production. As in Greenwood, Hercowitz and Huffman (1988), Finn (1991) and Greenwood, Hercowitz and Krussel (1992), we suppose that using capital more intensively increases the rate at which capital depreciates. Specifically, we assume that the time $t$ depreciation rate of capital, $\delta_{t}$, is given by

$$
\delta_{t}=\delta U_{t}^{\phi}
$$

where $0<\delta<1$ and $\phi>1$. The stock of capital evolves according to

$$
K_{t+1}=\left(1-\delta_{t}\right) K_{t}+I_{t}
$$

where $I_{t}$ denotes time $t$ gross investment. Under our assumptions, firms will not, in general, find it optimal to fully utilize the stock of capital, preferring to 'hoard' some capital so that they can use it more intensively when the returns to doing so are unusually large.

We assume that the level of technology, $X_{t}$, evolves according to

$$
X_{t}=X_{t-1} \exp \left(\gamma+v_{t}\right)
$$

where $v_{\mathrm{t}}$ is a serially uncorrelated process with mean 0 and standard deviation $\sigma_{v}$. The aggregate resource constraint is given by

$$
C_{t}+I_{t}+G_{t} \leq Y_{t}
$$

where $G_{t}$ denotes the time $t$ level of government consumption. We assume that $G_{t}$ evolves according to

$$
G_{i}=X_{1} g_{i}^{*}
$$


Here $g_{t}^{*}$ is the stationary component of government consumption. We assume that $g_{t}=$ $\ln \left(g_{i}^{*}\right)$ evolves according to

$$
g_{t}=\mu+\rho g_{t-1}+\epsilon_{t}
$$

where $\mu$ is a scalar, $|\rho|<1$ and $\epsilon_{t}$ is a serially uncorrelated process with mean 0 and standard deviation $\sigma_{c}$.

In the presence of complete markets, it is straightforward to show that the competitive equilibrium of this economy corresponds to the solution of the following social planning problem:

Maximize

$$
E_{0} \sum_{t=0}^{\infty} \beta^{t}\left[\ln \left(C_{t}\right)+\theta N_{t} \ln \left(T-\varsigma-W_{t} f\right)+\theta\left(1-N_{t}\right) \ln (T)\right]
$$

subject to (2), (3) and (5) - (8) by choice of contingency plans for $\left\{C_{t}, K_{t+1}, N_{t}, U_{t}, W_{t}\right.$ : $t \geq 0\}$.

To allow for a simple form of labor hoarding, we proceed as in Burnside, Eichenbaum, and Rebelo (1993) and assume that $N_{1}$ must be chosen before $X_{t}$ and $g_{t}$ are seen. Let $\Omega_{t}$ denote the information set that includes the lagged values of all time $t$ variables in the model. Let $\Omega_{i}$ consist of the union of $\Omega_{t}$ and $\left(X_{1}, g_{t}\right)$. We assume that $N_{t}$ is chosen on the basis of $n_{t}$ while $\left\{C_{t}, K_{t+1}, U_{t}, W_{t}\right\}$ is chosen on the basis of $\Omega_{t}$. This formulation of the problem incorporates the idea that firms must make employment decisions conditional on their views about the future state of demand and technology, and firms cannot adjust the number of employees instantly in response to the shocks affecting their environment. Once employment decisions are made, firms adjust to observed shocks along other dimensions. In Burnside, Eichenbaum and Rebelo (1993), the only way this adjustment can occur is via variations in the labor effort that workers are asked to supply. ${ }^{5}$ In this model, firms can also vary capital's effort, i.e. the utilization rate of capital.

Variations in capital utilization involve trade-offs between the effects on output and the effects on the depreciation rate of capital. We can examine these trade-offs by considering

\footnotetext{
"In (9) we have exploited the fact that, eince agente criterion functions are separable across conaumption and leiaure, the planner will equate the consumption of employed and unemployed individuals. In addition, wo have normalised the number of agente in the economy to one.

${ }^{5}$ Note that work effort, $W_{1}$, and ahift length, $f$, appear aymmetrically in production and preferences. As a result, the properties of ame aspects of the model are unchanged if the interpretations of these variables are reversed. For example, output's univariate dynamics are identical. However, as noted in BER (1993) reversing tho interpretation implies that all movements in labor input are observable, which has different implications for the joint behavior of output and average productivity.
} 
the planner's Euler equation for $U_{t}$ :

$$
(1-\alpha) \frac{Y_{t}}{U_{t}}=\phi \delta U_{t}^{\phi-1} K_{t}
$$

According to (10) the optimal plan for $U_{t}$ sets the marginal product of an increase in the utilization rate equal to the marginal change in depreciation of the capital stock. Other things equal, factors that increase the marginal product of capital utilization, such as $X_{t}$ and/or $N_{t}$ lead to an increase in the rate of capital utilization. (See section 4 for a more detailed discussion).

A number of related models are of interest. First, when the rate of capital utilization cannot be varied, the model reduces to that of Burnside, Eichenbaum and Rebelo (1993). For convenience we refer to this as the labor hoarding model. Second, if in addition, $N_{t}$ and $W_{t}$ are chosen after $X_{t}$ and $g_{t}$ are seen, then the model is observationally equivalent to the standard RBC indivisible labor model, modified to incorporate government consumption into the analysis, that is analyzed in Christiano and Eichenbaum (1992). For convenience we refer to this as the benchmark model.

In general it is not possible to solve any of these models analytically. Here we use King, Plosser and Rebelo's (1988) log linear solution procedure to obtain an approximate solution to the planning problem. According to our model, $K_{t+1} / X_{t}, Y_{t} / X_{t}, C_{t} / X_{t}, g_{t}, N_{t}$, $W_{t}$ and $U_{t}$ all converge in non-stochastic steady state. It is possible to write the planning problem entirely in terms of these variables. Let $k_{t+1}=\ln \left(K_{t+1} / X_{t}\right), y_{t}=\ln \left(Y_{t} / X_{t}\right)$, $c_{t}=\ln \left(C_{t} / X_{t}\right), w_{t}=\ln \left(W_{t}\right), n_{t}=\ln \left(N_{t}\right)$, and $u_{t}=\ln \left(U_{t}\right)$. Our (approximate) decision rules express $\left\{k_{t+1}, c_{t}, w_{t}, n_{t+1}, u_{t}\right\}$ as linear functions of $\left\{k_{t}, n_{t}, v_{t}, g_{t}\right\}$. We refer the reader to Burnside (1993) for details.

\section{Econometric Method}

In this section we discuss our methodology for estimating and evaluating the empirical performance of the factor hoarding model.

\subsection{Measuring Capital, Depreciation, Capital Utilisation and Labor Effort}

We face several problems in implementing our model. First, we do not have data on labor effort. In addition, existing measures of capital utilization are sector specific and subject 
to substantial measurement error (see Shapiro 1989). Second, our model implies that technology shocks cannot be measured by the Solow residual. The conventional method of calculating the Solow residual (at least in the RBC literature) begins from the assumption that output is produced via the Cobb-Douglas production function:

$$
Y_{t}=S_{t} K_{t}^{1-a} H_{t}^{a}
$$

where $H_{t}$ denotes total time $t$ hours worked. Given a consistent estimate of $\alpha$, the log of Solow residual can be computed using the relationship

$$
\ln \left(S_{1}\right)=\ln \left(Y_{t}\right)-(1-\alpha) \ln \left(K_{t}\right)-\alpha \ln \left(H_{1}\right)
$$

But, abstracting from measurement error in capital, our model implies that

$$
\ln \left(S_{t}\right)=\alpha \ln \left(X_{t}\right)+\ln \left(F_{t}\right)
$$

where the time $t$ factor hoarding component $F_{t}$ is given by

$$
\ln \left(F_{t}\right)=(1-\alpha) \ln \left(U_{t}\right)+\alpha \ln \left(W_{t}\right)
$$

Consequently shocks which cause capital utilization or labor effort to vary over time drive a wedge between actual technology shocks and the Solow residual. ${ }^{6}$

Third, we cannot measure capital using the official government data on the stock of capital. This is because, according to our model, the depreciation rate on capital varies as a function of the capital utilization rate. The official government data assumes (roughly speaking) a straight-line rate of depreciation over fixed service lives of different types of capital. ${ }^{7}$

Our strategy for dealing with these problems is as follows. To identify capital utilization we exploit functional form assumptions on the aggregate production technology and the assumption of perfect competition to derive a time series for $U$, that is a function of observable variables and a subset of the model's parameters. Given this time series,

\footnotetext{
-Allowing for measurement error in the capital atock induced by time varying capital utilisation rates (see below), the Solow residual in given by $\ln \left(S_{t}\right)=\alpha \ln \left(X_{t}\right)+\ln \left(F_{t}\right)+(1-\alpha)\left[\ln \left(K_{t}\right)-\ln \left(\bar{K}_{t}\right)\right]$ where $K_{t}$ is the true capital stock and $\bar{K}_{t}$ is the official neries.

${ }^{7}$ The offeial data do imply a time-varying depreciation eeries. However thio it an artifact of small changes in the distribation of the stock of capital across different typen of eapital. For details, see the Bureau of Economic Analyais (1993).
} 
we exploit the equilibrium relationship between effort, capital utilization and the Solow residual to measure effort and the actual shocks to technology.

Consider first the problem of measuring capital utilization. The planner's first order condition for $U_{1}$ equates the marginal product of an increase in capital utilization with the resulting increase in depreciation of the capital stock. Given our functional form assumptions, this condition can be expressed as:

$$
U_{t}=\left[\frac{(1-\alpha) Y_{1}}{\phi \delta K_{t}}\right]^{1 / \phi}
$$

Relation (15) allows us to deduce a time series for $U_{t}$ given a time series on $\left(Y_{t} / K_{6}\right)$ and values for $\alpha, \phi$ and $\delta$. $^{\circ}$

To identify effort, $W_{1}$, we exploit the fact that the linearized equilibrium law of motion for $W_{1}$ can be expressed as

$$
\ln \left(W_{t}\right)=\pi_{0}+\pi_{1} \ln \left(K_{t}\right)+\pi_{2} \ln \left(H_{t}\right)+\pi_{3} \ln \left(G_{t}\right)+\pi_{t} \ln \left(X_{t}\right)
$$

where $H_{i}$ equals total hours worked, $N_{t} f$. The scalars $\pi_{;}$are functions of the model's underlying structural parameters. The production function implies that

$$
\ln \left(X_{t}\right)=\alpha^{-1}\left[\ln \left(Y_{t}\right)-(1-\alpha) \ln \left(K_{t}\right)-(1-\alpha) \ln \left(U_{t}\right)-\alpha \ln \left(H_{t}\right)-\alpha \ln \left(W_{t}\right)\right]
$$

Given the time series on $U_{t}$ implied by (15), relations (16) and (17) can be solved to obtain a time series on $W_{t}$ and $X_{t}$ as functions of the observable variables $\left\{Y_{t}, K_{t}, H_{t}, G_{t}\right\}$ and the model's structural parameters.

To obtain a measure of the stock of capital we proceed as follows. The Euler equation for utilization, (10), can be solved for depreciation, as

$$
\delta_{t}=\frac{(1-\alpha)}{\phi} \frac{Y_{t}}{K_{t}} \text {. }
$$

Given data on $Y_{1}$, a vector of parameters and an initial value for $K_{1}$, we can calculate $\delta_{1}$ using (18). ${ }^{\circ}$ Then, using data on investment, $I_{1},(4)$ can be used to calculate $K_{1}$. This leads to a recursive procedure for determining the capital stock corresponding to any vector of parameters.

\footnotetext{
sIn our empirical analysis we only need to identify $\ln \left(U_{t}\right)$ up to a conatant. As a renult, we do not identify the parameter $\delta$.

We discuse the choice of initial value for $K_{\mathrm{L}}$ below.
} 


\subsection{Estimation and Diagnostic Procedures}

In order to estimate and diagnose the performance of our model we use a variant of the Generalized Method of Moments (GMM) procedure discussed in Christiano and Eichenbaum (1992). The basic idea underlying the procedure is as follows. The GMM criterion is set up so that the estimated model exactly matches the sample analog of certain unconditional moments of the data generating process. The model is then used to calculate various other second moments of the data. These other second moments can also be estimated in ways that do not involve the model. In population, the two sets of estimates ought to be the same. To test such hypotheses we use a simple Wald statistic discussed in Christiano and Eichenbaum (1992).

For the most part we report the results of testing only one moment restriction at a time in this paper. Our decision to do this reflects our view of the small sample properties of GMM based Wald test statistics. Using a version of the factor hoarding model as the data generating process Burnside and Eichenbaum (1994) show that asymptotic distribution theory typically provides a reasonable description of the small sample distribution of the Wald statistic when we look at individual moment restrictions. However (i) the small sample size of the Wald statistic increases rapidly as a function of the number of moments being tested, i.e. using asymptotic distribution theory, one rejects the model far more often than is warranted in small samples, (ii) even when testing a moderate number of moments, the small sample size is dramatically larger than the asymptotic size of the test, ${ }^{10}$ and (iii) the fundamental source of the problem has to do with the difficulty in estimating the optimal weighting matrix used in GMM based inference procedures.

We did not estimate the parameters $T, \beta, f$ and $\zeta$. Instead we fixed $T$ at 1369 hours per quarter, $\beta$ was set at $1.03^{-1 / 4}$ and $f$ was chosen so that the nonstochastic steady state value of effort equals one. We experimented with various values of $s$ and found that our results were insensitive to choices between 20 and 120 . The results reported here correspond to a value of 5 equal to 60 .

Let $\Psi_{1}$ denote the vector of remaining model structural parameters. As it turns out, we do not separately identify $\delta$ and $\phi$. However, we can identify $\delta=\delta U^{\star}$, where $U$ is the nonstochastic steady state value of $U_{t}$. Furthermore, as detajled in the Appendix, when

\footnotetext{
${ }^{10}$ For example, joint teats of fifteen moment restrictions that onght to have asymptotic sise of $5 \%$, typically have small omple (100 observations) oises exceeding $30 \%$.
} 
the first-order conditions of the planner's problem are evaluated in nonstochastic steady state, they lead to the parametric restriction

$$
\phi=\frac{\beta^{-1} \exp (\gamma)-1}{\bar{\delta}}+1
$$

Therefore, we do not estimate $\phi$ as a free parameter, and instead include $\bar{\delta}$ in our specification of $\Psi_{1}{ }^{11}$ In addition, we found that the variable $g_{t}=\ln \left(G_{t}\right)-\ln \left(X_{t}\right)$ exhibited a time trend in our sample. Consequently we allowed $g_{t}$ to depend on a constant, a time trend as well as one lag of itself. The parameters $g_{0}$ and $g_{1}$ denote the constant and the coefficient on time in this specification. With these modifications the $10 \times 1$ vector of structural parameters $\Psi_{1}$ is given by,

$$
\Psi_{1}=\left\{\theta, \bar{\delta}, \alpha, \gamma, \sigma_{v}, g / y, g_{0}, g_{1}, \rho, \sigma_{\varepsilon}\right\}
$$

In the Appendix we formally describe the unconditional moment restrictions used to define our GMM estimator for $\Psi_{1}$. Since our estimator is exactly identified, it has a very simple interpretation. Roughly speaking, the estimators of $\theta$ and $\alpha$ are chosen so that the model reproduces the sample average of per capita hours worked while satisfying, on average, the Euler equation for capital.

The log of our point estimate of $\bar{\delta}$ corresponds to the log of the eamfle average of the depreciation rate implied by the official data on capital and investment, $\tilde{\delta}_{t}=1+\left(I_{t}-\right.$ $\left.\dot{K}_{t+1}\right) / \bar{K}_{t}$. This corresponds to the assumption that, while the official measure of the capital stock, $\bar{K}_{t}$, does not match the actual capital stock on a quarter to quarter to basis, the Bureau of Economic Analysis does measure the average rate of depreciation correctly. Specifically, we assume that the population mean of $\bar{\delta}_{t}$ is the same as the population mean of $\delta_{\ell}$. Absent such an assumption the official and actual capital stock data would diverge over time. ${ }^{12}$

Our point estimate of the log of $g / y$ corresponds to the sample average of $\ln \left(G_{t}\right)-\ln \left(Y_{t}\right)$. Our point estimate of $\sigma_{v}$ equals the sample variance of the time series on $\ln \left(X_{t}\right)-\ln \left(X_{t-1}\right)$. The parameters $g_{0}, g_{1}$ and $\rho$ were estimated by regressing $g_{t}$ on a constant, $t$ and $g_{t-1}$.

\footnotetext{
${ }^{11}$ The fact that we do not identify $\delta$ and $U$ separately presente no diffculties in solving the model, as our log-linear approximation to the fint-order necensary conditions dependo only on $\delta$ and $\phi$.

${ }^{12}$ As it turns out our results are insensitive to how capital is meanued. Treating the official series as a measure of the true capital stock leads to qualitatively and quantitatively similar results. Different methods for choosing $K_{1}$ also lead to similar results.
} 
Finally, $\sigma$, was estimated by the sample standard deviation of the residuals from that regression.

Finally, we need to specify a value of $K_{1}$ in order to implement our strategy for obtaining a time series on the stock of capital. One choice would be $K_{1}=\bar{K}_{1}$. However, there is no a priori reason for this choice. We choose $K_{1}$ so that the resulting capital series, $K_{t}$, and the official capital stock series, $\tilde{K}_{t}$, imply the same average output-capital ratio. Since our model implies that deviations between $\bar{K}_{t}$ and $K_{t}$ are transitory, this moment restriction ought to hold in population. An advantage of imposing this choice in sample is that it results in an estimate of $\alpha$ that is very similar to that used in the literature.

To diagnose the empirical performance of our model we must estimate various moments of the data in ways that do not involve the model. Let $\Psi_{3}$ denote a vector of population moments to be estimated. These include objects like the relative standard deviations and dynamic correlations between different variables. In the Appendix we formally describe the unconditional moment restrictions underlying our estimator of $\Psi_{2}$ as well as our procedure for testing hypotheses.

One problem with specifying the elements of $\Psi_{3}$ is that variables like $C_{t}, Y_{t}, K_{t}, G_{t}$, and $A P L_{t}$ exhibit a marked trend. For the objects in $\Psi_{3}$ to be meaningful, they must refer to the moments of stationary time series. Depending on the context, we work with the stationary inducing transformation of the data discussed in Hodrick and Prescott (1980) and Prescott (1986) or with growth rates of different variables. ${ }^{13}$ Therefore the moments in $\Psi_{3}$ pertain to Hodrick and Prescott (HP) Giltered or first differenced time series. ${ }^{14}$ To assess the robustness of results obtained with HP filtered data we redid all of our calculations working with growth rates of the data. These are reported in an appendix to this paper that is available upon request. As it turns out, the choice of whether to work with growth rates or HP filtered data has little impact on our qualitative results.

\footnotetext{
${ }^{13}$ That the HP filter is a otationary inducing traneformation for difference atationary atochastic process follows directly from resulto in King and Rebelo (1993b).

14 The data used to estimate $\Psi_{1}$ were not HP filtered or frat differences. In all cases, the unconditional moments used to eatimate the models' otroctural parametern pertain to ratios of variables like $Y_{1} / K_{*}$ thal are stationary stochastic processes according to our model.
} 


\subsection{Data}

Private consumption, $C_{t}$, was measured as the sum of private sector expenditures on nondurable goods plus services plus the imputed service flow from the stock of durable goods. The first two measures were obtained from the Survey of Current Business. The third measure was obtained from Brayton and Mauskopf (1985). Government consumption, $G_{t}$, was measured by real government (federal, state and local) purchases of goods minus real government investment. The government data was provided to us by John Musgrave at the Bureau of Economic Analysis. The official capital stock, $\bar{K}_{t}$, was measured as the sum of consumer durables, producer structures and equipment, and government and private residential capital plus government non-residential capital. Data on gross investment, $I_{t}$, are the flow data that conceptually match the capital stock data. Gross output, $Y_{f}$, was measured as $\left(C_{t}+G_{t}+I_{t}\right)$ plus time $t$ inventory investment. Our basic measure of hours worked is the quarterly time series constructed by Hansen (1984), which we refer to as household hours. The data cover the period 1955:3-1984:1 and were converted to per capita terms using an efficiency weighted measure of the population. ${ }^{15}$ We use Prescott's (1986) model of measurement error in hours worked. In particular we assume that the $\log$ of measured hours worked differs from the log of actual hours worked by an i.i.d. random variable that has mean zero and standard deviation $\sigma_{\xi}$. To estimate $\sigma_{\xi}$ we need two measures of hours worked. The first is Hansen's measure of hours worked which is based on the household survey conducted by the Bureau of the Census. The second is the establishment survey conducted by the Bureau of Labor Statistics. The Appendix provides details regarding the estimation procedure and how measurement error affects the moment restrictions that define our estimator of $\boldsymbol{\Psi}_{1}$.

\section{Empirical Results}

Columns 1 and 2 of Table 1 report parameter estimates for the benchmark and factor hoarding models, respectively. A number of interesting results can be seen here. First, except for $\sigma_{v}$, the standard deviation of the technology shock, the parameter estimates for both models are very similar. This greatly facilitates comparisons across the models. Note in particular that $\alpha$ is estimated to equal 0.642 and 0.655 in the factor hoarding and

\footnotetext{
${ }^{15}$ See Christiano (1988, appendix) for further details.
} 
benchmark models, respectively. So the time series on the Solow residual that emerge from the two models are very similar to those used in existing RBC analyses (see for example Hansen (1985) and Prescott (1986)). Second, the estimated value of $\bar{\delta}(.0208)$ implies that $\phi$ is roughly equal to 1.54 , so that the concavity restriction on the depreciation technology is satisfied $(\phi>1)$. Third, the expected value of the rate of depreciation, $\delta_{l}$, is equal to .0208 (or an expected annual rate of depreciation of $8.6 \%$ ). The implied two standard deviation band for quarterly depreciation is $(.0191, .0226) .^{16}$

Figure 1 displays the time series on the capacity utilization rate implied by our model. ${ }^{17}$ We also display the Federal Reserve's measure of capacity utilization for the manufacturing sector. There are at least two reasons why the time series might differ: (i) our measures of output and capital cover a broader segment of the economy than the Fed's, and (ii) the Fed's measure is subject to substantial measurement error (see Shapiro (1989)). Still it is comforting that the series track each other reasonably well.

Next, notice that, according to our model, capital utilization is quite volatile. In particular, our point estimates imply that the standard deviation of the growth rate of the effective stock of capital $\left(U_{l} K_{t}\right)$ equals 0.0068 whereas the standard deviation of the growth rate of the stock of capital equals 0.0015 . Focusing on the physical stock of capital would give a very misleading picture of the volatility of effective capital input.

Finally, notice that incorporating factor hoarding into the analysis leads to a substantially smaller estimate of the volatility of technology shocks. Relative to the benchmark model, correcting for factor hoarding leads to a $58 \%$ reduction in the variance of the innovation to technology shocks. To assess how much of this decline is attributable to time varying effort as opposed to variable capital utilization, we estimated the labor hoarding version of the model in which $U_{t}$ is set equal to its non-stochastic steady state value. ${ }^{18}$ Correcting for labor hoarding alone leads to a $21 \%$ reduction in the variance of the inno-

\footnotetext{
${ }^{16}$ Recall that $E\left(\delta_{1}\right)=\delta E\left(U_{i}^{\phi}\right)=\delta E\left\{\exp \left|\phi \ln \left(U_{1}\right)\right|\right\}$. Asuming that the underlying diaturbances to the economy are normally distributed, $\ln \left(U_{1}\right)$ is normally dintributed with mean $\mu_{0}$ and variance $\sigma_{\text {.. }}$. It follow that $E\left(\delta_{1}\right)=\delta \exp \left(\phi \mu_{0}\right) \exp \left(\frac{1}{2} \phi^{2} \sigma_{0}^{2}\right)$. Using the fact that, in our model, the $\log$ of the steady otate of a variable is equal to the expected value of the log of that variable, we obtain $\delta \exp \left(\phi \mu_{*}\right)=\delta U^{\star}=$ $\delta$. So $E\left(\delta_{4}\right)=\delta \exp \left(\frac{1}{2} \phi^{2} \sigma_{0}^{2}\right)$. Solving the model we obtain $\sigma_{0}=0.027$. The variance of $\delta_{1}$ is given by $E\left(\delta_{t}^{2}\right)-\left[E\left(\delta_{t}\right)\right]^{2}=\delta^{2}\left[\exp \left(2 \phi^{2} \sigma_{*}^{2}\right)-\delta^{2} \exp \left(\phi^{2} \sigma_{*}^{2}\right)\right]$.

if To produce this graph, we have chowen $\delta=0.0285$.

It This model is clocely related to the one analysed in BER (1993). One important difference is that, here, $X_{1}$ is assumed to be a difference atationary stochastic proceso. BER (1993) assume that $X_{1}$ is a trend atationary process.
} 
vation to technology shocks. ${ }^{10}$ Evidently capital utilization plays a larger role than labor hoarding in reducing the estimated volatility of technology shocks.

\subsection{Some Simple Diagnostics}

Before discussing the quantitative role of variable capital utilization in propagating shocks, we briefly assess the performance of the benchmark and factor hoarding models in terms of their ability to account for some of the standard statistics emphasized in the RBC literature. Columns 1 and 2 of Table 2 present the implications of the two models for the volatility of consumption, investment and hours worked relative to output and the volatility of hours worked relative to average productivity $\left\{\sigma_{e} / \sigma_{v}, \sigma_{i} / \sigma_{v}, \sigma_{k} / \sigma_{v}\right.$ and $\left.\sigma_{k} / \sigma_{o p i}\right\} .^{20}$ Column 3 reports non-model based estimates of these moments. Numbers in parentheses are the standard errors of the corresponding point estimates. Numbers in brackets are the probability values of the $W$ statistics discussed in the Appendix for testing whether the model and data population moment are the same. Notice that both models do very well on these dimensions of the data. In no case can we reject the individual hypotheses that were investigated (at even the $15 \%$ significance level).

Next we consider the models' implications for the dynamic correlations between hours worked and average productivity as well as the dynamic correlations between average productivity and output. These are summarized in Figures 2 and 3, respectively. Columns 1 and 2 of these figures pertain to the benchmark and factor hoarding models. The dotted lines in row 1 correspond to non-model based estimates of $\rho\left(A P L_{l}, H_{t+i}\right): i=$ $\{-4,3, \ldots, 0, \ldots, 3,4\}$ and $\rho\left(A P L_{l}, Y_{t+i}\right): i=\{-4,3, \ldots, 0, \ldots, 3,4\}$ while the solid lines denote the values of those moments implied by the models. The solid lines in row 2 graph the difference between model and non-model based estimates while the dotted lines denote a two standard deviation band for this difference.

From Figure 2 we see that the factor hoarding model does quite well at accounting for the individual dynamic correlations between average productivity, hours worked and output. Let $\rho^{D}\left(A P L_{l}, H_{1+i}\right)$ and $\rho^{D}\left(A P L_{t}, Y_{t+i}\right)$ denote the difference between model and non model values of $\rho\left(A P L, H_{t+i}\right)$ and $\rho\left(A P L_{l}, Y_{t+i}\right), i=\{-4,-3, \ldots, 0, \ldots,+3,4\}$. According to Figure 2, we cannot reject the individual bypotheses that $\rho^{D}\left(A P L_{l}, H_{1+i}\right)=0$

\footnotetext{
${ }^{10}$ Our point eatimate of $\sigma_{v}$ in the labor hourding model equals 0.012 with a atandard error of 0.0007 .

${ }^{20}$ These refer to moments of the HP Gitered data.
} 
for $\{i=-2,-2,1, \ldots, 4\}$. Comparing the relative performance of the benchmark and factor hoarding models, we see that the latter seems more consistent with the asymmetric lead lag relationship between average productivity and hours worked, although these differences are not particularly marked once sampling uncertainty is taken into account.

Turning to Figure 3 we see that the models also do quite well at accounting for the dynamic correlations between average productivity and output. In the case of the factor hoarding model, we cannot reject the hypothesis that $p^{D}\left(A P L, Y_{1+i}\right)$ for $\{i=-2,-1, \ldots, 4\}$. For the benchmark model we cannot reject the hypothesis that $\rho^{D}\left(A P L, Y_{t+i}\right)$ for $\{i=$ $-1, \ldots, 4\}$.

\subsection{Propagation of Shocks}

We now consider the implications of factor hoarding for the propagation of shocks to agents' environments and the volatility of output. Rows 1,2 and 3 of Table 3 report a variety of statistics pertaining to the volatility of output. Column 1 reports the value of $\sigma_{y}$ implied by the different models. Column 2 reports our estimate of $\sigma_{y}$ in the data. Numbers in parentheses denote standard errors. Column 3 reports the $W$ statistic for testing the hypothesis that the model value of $\sigma_{v}$ equals the data population value of $\sigma_{v}$. The number in brackets equals the probability value of the corresponding $w$ statistic.

Table 3 reveals that it is very difficult to distinguish between the models on the basis of their ability to account for the volatility of output. Specifically, we cannot reject, at even the $25 \%$ significance level, the null hypotheses that the values of $\sigma_{v}$ for the benchmark and factor hoarding models both equal the data population value of $\sigma_{v}$. There is some marginal evidence against this hypothesis for the labor hoarding model (it can be rejected at the $10 \%$ but not at the $5 \%$ significance level). But, all in all, the three models do quite well at accounting for the volatility of aggregate output. ${ }^{21}$

What distinguishes arnong the models is how they account for the volatility of output. The estimated volatility of technology shocks is very different in the three models. But all of them can account for the volatility of output.23 Since the estimated volatility of

\footnotetext{
${ }^{21}$ Thin evidence is robust to using the first-difference filter to render output stationary. In this case, the p-values are 0.08 for the benchmark model, 0.42 for the labor hoarding model and 0.40 for the factor hoarding model.

${ }^{23}$ Recall that the estimated law of motion for $g_{t}$ is very vimilar in the different modele, so that this cannot account for large differences among them.
} 
technology shocks is smallest in the factor hoarding model, factor hoarding must somehow act to magnify and propagate those shocks.

Before analyzing how factor hoarding does this, we first quantify the relative strength of the internal propagation mechanisms in the different models. One simple way to do this is to compare the variability of output when the propagation mechanisms in the models are and are not operative. According to the factor hoarding model, hours worked, effort, capital utilization and $K_{t} / X_{1-1}$ are stationary stochastic processes. Consequently the log level of output can be represented as

$$
\ln \left(Y_{t}\right)=\ln \left(X_{t}\right)+y_{t}
$$

where $y_{t}$ represents the time $t$ stationary deviation of the log of output away from its trend path. We can think of $y_{t}$ as corresponding to the part of output variation that is explained by the model's internal mechanisms for propagating shocks, as distinct from the variation that is due directly to (exogenous) movements in $X_{t}$.

Suppose that we shut down these propagation mechanisms. In particular, suppose that hours worked, effort and capital utilization equal their constant non-stochastic steady state values and that $K_{t}$ varies in direction proportion to $X_{t-1}$, with $K_{t}=k \exp \left(X_{t-1}\right)$. Here $k$ denotes the nonstochastic steady state value of $K_{t} / X_{t-1}$. Then output, $Y_{t}^{*}$, evolves according to

$$
\ln \left(Y_{i}^{*}\right)=\ln \left(X_{t}\right)+y
$$

where $y$ denotes the non-stochastic steady state value of $y_{8}$.

One measure of propagation is the standard deviation of $\ln \left(Y_{1}\right)$ relative to the standard deviation of $\ln \left(Y_{i}^{*}\right)$. Since the latter equals the standard deviation of $\ln \left(X_{i}\right)$, we denote this ratio by $\sigma_{v} / \sigma_{z}$. This statistic can be calculated for all three models by applying a stationary-inducing filter to both $\ln \left(Y_{t}\right)$ and $\ln \left(X_{t}\right){ }^{23}$ Columns 4 and 5 of Table 3 report $\sigma_{z}$ and $\sigma_{v} / \sigma_{z}$, respectively, using the HP filter.

A number of interesting results emerge here. First, in the case of the benchmark model, $\sigma_{v} / \sigma_{z} \approx 1.05$, i.e. the propagation mechanisms embedded in that model generate only a $5 \%$ increase in the volatility of output. In contrast, the propagation mechanisms

\footnotetext{
${ }^{23}$ In principle one could either shut down the shocks to gt or ahut down the shocks to $X$, when performing these calculations. Since shocks to $g_{t}$ contribute very little to the volatility of output, we allowed for both shocks.
} 
embedded in the factor hoarding model lead to a $47 \%$ increase in the volatility of output $\left(\sigma_{v} / \sigma_{z} \approx 1.47\right)$. Second, $\sigma_{y} / \sigma_{z}$ is actually lower in the labor hoarding model than in the benchmark model (1.01 versus 1.05). This finding is consistent with the fact that, of the three models, the value of $\sigma_{y}$ is lowest in the labor hoarding model. ${ }^{24}$

A different way to assess the importance of factor hoarding as a propagation mechanism is to consider the dynamic response functions of different variables in the factor hoarding and benchmark models to shocks in $X_{t}$ and $g_{t}$. Rows 1 and 2 of Figure 4 report the dynamic response of the log level of output to $1 \%$ shocks in $X_{t}$ and $g_{t}$. Columns 1 and 2 pertain to the benchmark and factor hoarding models, respectively. The dotted lines denote a two standard deviation band about the impulse response functions. ${ }^{25}$

Consider the effect of a $1 \%$ shock to $X_{1}$. In the impact period, the response of output is quite similar in the two models, with $Y_{t}$ rising by $1.043 \%$ in the benchmark model and $1.078 \%$ in the factor hoarding model. Thereafter, the response path is different. In the benchmark model, output smoothly declines to its new steady state growth path, approaching it from above. In the factor hoarding model, the one period ahead effect is larger than the impact effect ( $1.51 \%$ versus $1.078 \%$ ). Thereafter output smoothly declines to its new steady state growth path, approaching it from above. Notice that the rate of convergence is reasonably slow with output up by more than $1.1 \%$ twenty four quarters after the technology shock. Row 2 of Figure 4 reveals a similar if less dramatic pattern in the case of a shock to $g_{1}$. So, as with a shock to $X_{t}$, factor hoarding serves, at least after a one period delay, to magnify and propagate the effects of the shock to $g_{t}$.

Figure 5 displays the dynamic response functions of the log of hours worked in the benchmark and factor hoarding models to $1 \%$ shocks in $X_{t}$ and $g_{t}$. In the impact period of the shock to $X_{t}$, hours worked rise by roughly $0.59 \%$ in the benchmark model and then smoothly return to their (unaffected) non-stochastic steady state level. In the factor hoarding model, hours worked do not, by construction, respond contemporaneously to a shock in $X_{1}$. In the period after the shock they rise by $0.8 \%$ and then slowly converge to their (unaffected) non-stochastic steady state level. Notice that, after the impact period of the shock, the rise in hours worked in the factor hoarding model exceeds the corresponding

\footnotetext{
${ }^{24}$ These reaulw are robust to the filter applied to $\ln \left(Y_{t}\right)$ and $\ln \left(X_{1}\right)$. Specifically, for the first-difference filter $\sigma_{y} / \sigma_{z}$ is 1.05 for the benchmark model, 0.89 for the labor hoarding model and 1.19 for the factor hoarding model.

${ }^{25}$ These banda reflect ampling ancertainty in our entimates of the model'structural parameters.
} 
rise in the benchmark model along the entire adjustment path to non-stochastic steady state. A similar pattern is observed in the response of the two models to a shock in $g_{t}$.

The reason for the 'hump-shaped' response of output to shocks in the factor hoarding model can be understood by considering the dynamic response functions of the log of effort and the log of capital utilization in that model. These are displayed in Figure 6. ${ }^{26}$

In the impact period of the shock to $X_{t}$, effort rises by $0.29 \%$ and then immediately reverts to its non-stochastic steady state level. The absence of a persistent response in effort reflects our assumption that it is costless to adjust hours worked in the period after the shock. By contrast, capital utilization initially rises by $0.7 \%$ and then climbs by even more (to $0.96 \%$ ) in the next period. Thereafter capital utilization smoothly approaches its (unaffected) steady state level from above. To understand the hump shaped response of capital utilization, notice that impact period response of effort is small relative to the second period response of hours worked. ${ }^{27}$ Therefore, the response of the log of effective labor input, being the sum of the $\log$ of effort and the $\log$ of hours worked responses displays a hump shape pattern. It is not surprising that utilization, being a complement to labor input, displays a similar, hump-shaped response to shocks. Since variations in effort, hours and utilization account for most of the transitory movement in output, the level of output also displays a hump-shaped response. Similar patterns arise in response to shocks to $g_{t}$.

To gain further intuition for our results, it is useful to consider the dynamic response functions of consumption and investment to $1 \%$ shocks in $X_{t}$ and $g_{t}$. These are displayed in Figures 7 and 8, respectively. We begin by discussing the case of a technology shock. Equation (5) implies that a $1 \%$ technology shock leads to a permanent $1 \%$ increase in the level of $X_{t}$. Given the balanced growth nature of our model, this generates a $1 \%$ upward shift in the steady state growth path of $C_{t}, K_{t}, I_{t}, G_{t}$ and $Y_{t}$. To build up the capital stock, investment must approach its new steady state growth path from above. ${ }^{28}$ Other things equal, this suggests that consumption will approaches its new steady state path from below. By increasing capital utilization and labor effort in the impact period

\footnotetext{
${ }^{20}$ Given our normalisations, the response function of capital atilisation is proportional to the response function of depreciation, provided that we interpret the vertical axes as denoting the percent deviation of depreciation from its non-stochatic steady state value. The factor of proportionality in equal to $\phi$.

${ }^{27}$ This reflects the relative curvature of agents' preferences over effort and employment.

2a This corresponds to $K_{8}$ approaching its steady atate growth path from below.
} 
of the shock, the planner can generate a more than $1 \%$ output change in response to a $1 \%$ technology shock even though hours are fixed. Given the concavity of the planner's criterion function in $C_{1} / X_{1}$, and the resulting desire of the planner to smooth consumption relative to its new steady state growth path, the optimality of this type of response is not surprising.

In the period after the shock, there is a large increase in hours worked and capital utilization. This accounts for the large percentage increase in output that occurs in the period after the shock. This extra output allows for a burst of investment while consumption continues to climb upwards to its new steady state growth path. Thereafter, hours worked, capital utilization and investment smoothly fall towards their steady state paths from above, while consumption continues to climb to its steady state path from below.

Consistent with this interpretation of factor hoarding, Figure 7 reveals that consumption approaches its new steady state growth path more quickly in the factor hoarding model than in the benchmark model. We can quantify the speed of adjustment by calculating how many periods it takes consumption to climb $75 \%$ of the way to its new steady state growth path. In the factor hoarding model, this occurs within 4 periods, but in the benchmark model this takes 15 periods. Notice that factor hoarding also serves to speed the convergence of consumption to its steady state growth path after a shock to $g_{t}$. The key difference is that the steady state growth paths of $C_{t}, K_{t}, I_{t}, Y_{t}$ and $G_{t}$ are unaffected by a shock to $g_{t}$.

Figure 9 depicts the dynamic response of the Solow residual in the factor hoarding model to $1 \%$ shocks in $X_{t}$ and $g_{t}$. The key point here is that factor hoarding induces a large persistent deviation between the actual technology shock and the measured Solow residual. In the impact period of the shock both effort and capital utilization rise. Since the Solow residual is calculated using measured hours worked and the stock of capital, it rises by more than implied by the shock to technology ( $1.07 \%$ versus $0.64 \%)$. In the periods after the shock, effort reverts to its steady state level but capital utilization continues to be high relative to its steady state level. Consequently the Solow residual continues to be above its (new) steady state growth path of $0.64 \%$. As capital utilization slowly declines to its steady state level, the Solow residual approaches its steady state growth path from above. Naive Solow residual accounting which attributes all of the movements in total factor productivity to movements in $X_{b}$, clearly overstates the volatility of technology 
shocks. In contrast to the labor hoarding model considered in Burnside, Eichenbaum and Rebelo (1993), the deviation between the Solow residual and the technology shock is highly persistent, reflecting the persistent deviation of capital utilization from its steady state level. This is the basic reason that our model generates a much smaller estimate of the volatility of technology shocks than do the labor hoarding and benchmark models.

Finally, note that in response to a $1 \%$ shock in $g_{t}$, the Solow residual initially rises (by roughly $.07 \%$ ) and then slowly approaches its unchanged steady state value from above as capital utilization reverts to its unchanged steady state value. Again, naive Solow residual accounting overstates the volatility of technology shocks. Indeed here the analyst would infer that a sequence of technology shocks has occurred even though there has only been a one time shock to aggregate demand and no shock to technology whatsoever.

\subsection{Persigtence of Output Growth}

Cogley and Nason (1993) discuss the propagation mechanisms in RBC models by focusing on the autocorrelation function of output growth. They show that many RBC models imply that the growth rate of output is close to being a white noise process. In contrast, the actual growth rate of U.S. output displays positive persistence. Cogley and Nason (1993) interpret this discrepancy as reflecting the weakness of the propagation mechanisms embedded within standard RBC models. A simple way to see this is to recall that output can be decomposed according to:

$$
\ln \left(Y_{t}\right)=\ln \left(X_{t}\right)+y_{t}
$$

Under our assumptions about $X_{t}$, the growth rate of output is given by

$$
\Delta \ln \left(Y_{t}\right)=\gamma+v_{t}+\Delta y_{t}
$$

where $v_{t}$ is white noise. The absence of significant correlation in (model) output growth reflects the fact that, in standard RBC models, $v_{1}$ is the dominant stochastic component of $\Delta \ln \left(Y_{t}\right)$. The key question addressed in this subsection is whether the propagation mechanisms in the factor hoarding model are sufficiently strong so as to allow it to quantitatively account for the autocorrelation function of $\Delta \ln \left(Y_{t}\right)$.

The first row of Figure 10 illustrates our unconstrained estimates of the autocorrelation function of $\Delta \ln \left(Y_{t}\right)$ as well as those implied by the benchmark and factor hoarding 
models. As noted above, the actual growth rate of U.S. output is positively autocorrelated: specifically the first two autocorrelation coefficients are positive and significant. Though it is difficult to discern from Figure 10, the benchmark model implies that all the autocorrelations are negative. In contrast, the factor hoarding model does very well at accounting for the autocorrelation function of $\Delta \ln \left(Y_{t}\right)$. The joint hypothesis that the first two autocorrelation coefficients implied by the factor hoarding model are the same as those in the data cannot be rejected at conventional significance levels. This hypothesis is strongly rejected for the case of the benchmark model.

The impulse response functions discussed in the previous section provide some intuition for these results. In the benchmark model, $\Delta \ln \left(Y_{1}\right)$ is significantly affected only in the impact period of a technology shock. It follows that since innovations to technology are a white noise process, output growth closely resembles white noise. In the factor hoarding model, a $1 \%$ shock to technology causes output to rise by $1.08 \%$ in the period of the shock. In the second period after the shock output climbs by an additional $0.43 \%$. So the initial spurt in output growth is a signal of further growth in output. A similar pattern is observed in response to shocks to $g_{l}$. Not surprisingly, the growth rate of output is predicted to display positive serial correlation.

Notice from the second row of Figure 11, that both models predict the correct pattern of autocorrelation in the growth rate of the Solow residual. ${ }^{29}$ So the factor hoarding model is able to generate positive serial correlation in output growth without generating counterfactual predictions for the growth rate of the Solow residual. This is not the case for the benchmark model. It must choose which of the two correlation structures to match. As things stand, it matches the correlation structure of $\Delta \ln \left(S_{t}\right)$ but not $\Delta \ln \left(Y_{t}\right)$. We could improve the model's performance regarding $\Delta \ln \left(Y_{t}\right)$ by assuming that $\Delta \ln \left(S_{t}\right)$ is positively serially correlated but this would simply substitute one counterfactual implication for another.

We can obtain a slightly different perspective on the performance of the models by examining their implications for the spectrum of output growth:

$$
f(\omega)=\operatorname{Var}\left[\Delta \ln \left(Y_{t}\right)\right]\left[1+2 \sum_{j=1}^{\infty} \cos (j \omega) \rho_{j}\right],
$$

\footnotetext{
${ }^{20}$ The benchmark model predict: negative serial correlation because we allow for i.i.d. meanurement error in hours worked. The factor boarding model makes the correlation slightly more negative.
} 
where $\rho_{j}$ is the $j$ th autocorrelation of output growth. The spectrum implied by the estimated benchmarl and factor hoarding models, as well as an unconstrained estimate, are presented in Figure 12. For the benchmark model the spectrum of $\Delta \ln \left(Y_{t}\right)$ is almost identical to the spectrum of $\Delta \ln \left(X_{1}\right)$. The model adds almost no volatility over and above the direct effect of the shocks, nor does the structure of the model significantly alter the spectral shape of the technology shocks. In contrast, the factor hoarding model magnifies the volatility of technology shocks in addition to significantly distorting their spectral shape. Notice in particular that it induces a significant spectral peak in output growth at business cycle frequencies from technology shocks which do not have a spectral peak.

\subsection{Alternate Measures of Cyclical Behavior}

In this subsection we assess the ability of the factor hoarding model to account for a subset of the diagnostic statistics emphasized by Rotemberg and Woodford (1994). These pertain to the time series properties of the forecastable component of the growth in economic aggregates like real output. To motivate these diagnostic statistics, it is useful to note the connection between the expected growth of a variable at different forecast horizons and the cyclical component of that variable as defined by Beveridge and Nelson (1981). Suppose that we define the trend in a difference stationary random variable $X_{t}$ as

$$
X_{t}^{T}=\lim _{k \rightarrow \infty} E_{t}\left(X_{t+k}-k \gamma\right),
$$

where $\gamma$ is the unconditional mean of the growth rate of $X_{t}$. The cyclical component of $X_{t}$ at time $t$ is just $X_{t}^{C}=X_{t}-X_{t}^{T}$, or

$$
X_{t}^{c}=-\lim _{k \rightarrow \infty} E_{t}\left(X_{t+k}-X_{t}-k \gamma\right)
$$

So the cyclical component of $X_{t}$ is negative whenever the series is expected to grow more in the long run than predicted by its unconditional mean growth rate. Strictly speaking, the cyclical component of $X_{t}$, so defined, is directly related to forecastable changes in $X_{t}$ at the infinite horizon. This motivates Rotemberg and Woodford's (1994) desire to focus on forecastable changes in output (and other variables) at various finite horizons. Note that if output was a random walk, as it is (approximately) in the benchmark model, it could (and does) exhibit substantial variation even if its cyclical component is identically equal to zero. As long as the cyclical component of aggregate U.S. output is not i.i.d., the 
benchmark RBC model will not be able to account for any of its variation, even if it could account for all of the variance in the actual growth rate of output.

To generate the forecasts needed to make their diagnostic tests operational, Rotemberg and Woodford (1994) use a second-order VAR representation for the growth rate of output, the $\log$ of hours worked and the log difference between consumption and output. In light of this, we too estimated an unconstrained second-order VAR for these variables. We then calculated the population values of the VAR implied by the estimated benchmark and factor hoarding models. ${ }^{30}$ Unlike Rotemberg and Woodford (1994), the VARs implied by our models do not have singular innovation covariance matrices. This is because we allow for three sources of randomness in the variables observed by the econometrician: shocks to technology, shocks to government purchases and classical measurement error in hours worked.

Let $\hat{Y}_{i, k}, \hat{H}_{i, k}$, and $\widehat{A P L} L_{i, k}$ denote the forecastable components of the $k$ period ahead growth of output, the log of hours worked and average productivity:

$$
\begin{aligned}
\hat{Y}_{t, k} & =E_{t}\left[\ln \left(Y_{t+k}\right)-\ln \left(Y_{t}\right)\right] \\
\hat{H}_{t, k} & \left.=E_{t}\left[\ln \left(H_{t+k}\right)\right]-\ln \left(H_{t}\right)\right] \\
\widehat{A P} L_{t, k} & =E_{t}\left[\ln \left(A P L_{t+k}\right)-\ln \left(A P L_{t}\right)\right]
\end{aligned}
$$

We consider the ability of the benchmark and factor hoarding models to account for (i) the volatility of $\hat{Y}_{i, k}, \hat{H}_{i, k}$, and $\widehat{A P} L_{t, k}$, (ii) the correlations among these variables, and (iii) the correlation between $\hat{Y}_{t, k}$ and $\Delta \ln \left(Y_{t}\right), \ln \left(C_{t}\right)-\ln \left(Y_{t}\right), \ln \left(H_{t}\right)$ and $\Delta \ln \left(A P L_{t}\right)$.

Results for (i) and (ii) are summarized in Figure 13, while results for (iii) are summarized in Figure 14. Column 1 of each graph depicts point estimates of the relevant moments calculated from the unconstrained VAR and the models. Column 2 depicts the difference between the benchmark model and unconstrained VAR estimates along with a two standard error band around the difference. Column 3 is the same as Column 2 except that it pertains to the factor hoarding model.

Consider first the models' ability to account for the standard deviation of $\hat{Y}_{t, k}, \hat{H}_{t, k}$ and $\widehat{A P} L_{i, k}$. Figure 13 indicates that the most important failing of the benchmark model in this regard lies in its inability to generate sufficient variation in the predictable component

\footnotetext{
${ }^{30}$ The diagnostic statiatica which we discuse can be calculated from these VAR'a. $A$ detailed appendix is available from the authors opon request.
} 
of output growth. In fact, this model generates virtually no variation in $\hat{Y}_{t, k}$. This is consistent with our finding that output is close to being a random walk in the benchmark model. Figure 14 indicates that the factor hoarding model does considerably better at accounting for the standard deviation of $\hat{Y}_{t, k}$.

Next consider the correlation of $\hat{Y}_{t, k}$ with $\hat{H}_{t, k}$ and $\widehat{A P} L_{t, k}$. From Figure 13 we see that both models do very well at matching the strong positive correlation between $\hat{Y}_{t, k}$ and $\hat{H}_{t, k}$ found in the data at long forecast horizons. However, neither model fully accounts for the magnitude of the correlation found at short horizons $(k \leq 8)$. Still the factor hoarding model does better on this dimension than the benchmark model, in that it predicts a stronger positive correlation at short forecast horizons. Both models do a reasonably good job of matching the correlations between $\hat{Y}_{t, k}$ and $\widehat{A P} L_{t, k}$ at short forecast horizons. In large part this 'success' reflects the imprecision with which those correlations are estimated. The performance of both models deteriorates somewhat at longer forecast horizons, although the factor hoarding model does better than the benchmark model.

Finally, consider the models' implications for the correlations between $\hat{Y}_{t, k}$ and $\Delta \ln \left(Y_{t}\right)$, $\ln \left(C_{t}\right)-\ln \left(Y_{t}\right), \ln \left(H_{t}\right)$ and $\Delta \ln \left(A P L_{t}\right)$. Figure 14 indicates that the most important failings of the benchmark model lie in

1. its inability to account for the strong positive correlation between $\Delta \ln \left(Y_{t}\right)$ and $\hat{Y}_{t, k}$ at short forecast horizons, and

2. its inability to generate a positive correlation between $\Delta \ln \left(A P L_{t}\right)$ and $\hat{Y}_{t, k}$ at all forecast horizons.

These failures reflect the nature of the propagation mechanisms embedded in the benchmark model. Recall that in that model, output initially responds by just over $1 \%$ to a $1 \%$ shock in technology. Thereafter output is expected to decline to its long-run path. So other things equal, the model predicts a counterfactually negative correlation between the current change in output and the expected growth rate of future output relative to the current level of output. Since average productivity also rises in the impact period of the shock, the model also generates a counterfactually negative correlation between the growth rate of average productivity and the expected growth rate of output.

Figure 14 reveals that the factor hoarding model does significantly better at accounting for these features of the data. Indeed the model fully accounts for the correlations between 
$\hat{Y}_{t, k}$ and $\Delta \ln \left(Y_{t}\right)$ as well as the correlations between $\hat{Y}_{i, k}$ and $\Delta \ln \left(A P L_{t}\right)$. To see why, recall that, in the factor hoarding model, output initially rises by $1.08 \%$ in response to a $1 \%$ technology shock. In the period after the shock output continues to grow, climbing $1.51 \%$ above its initial level. So the initial $1.08 \%$ increase is followed by another predictable $0.43 \%$ increase. Thereafter, output falls steadily. However, it does not return to the level it attained in the impact period of the shock until more than 24 quarters have elapsed. So the initial positive growth rate in output, $\Delta \ln \left(Y_{t}\right)$, is expected to be followed by at least 24 quarters of growth relative to the time $t$ level of output. So here we expect $\Delta \ln \left(Y_{t}\right)$ to be positively correlated with $\hat{Y}_{t, k}$ for a large range of $\mathbf{k}$. Since the impact period response of average productivity is identical to the output response the model also generates positive correlations between $\Delta \ln \left(A P L_{t}\right)$ and $\hat{Y}_{t, k}$.

We conclude that while there are certainly dimensions along which the factor hoarding model does not fully account for the diagnostic statistics proposed by Rotemberg and Woodford it does substantially better than the benchmark model.

\section{Conclusion}

This paper formulated and estimated an equilibrium business cycle model in which capital utilization rates vary over the business cycle. We argue that cyclical movements in effective capital services are substantially more volatile than cyclical movements in the stock of capital. In addition we argued that variable capital utilization rates are a quantitatively important source of propagation to business cycle shocks. Because of this feature, our model is able to account for various features of post war business cycles that are anomalous from the perspective of existing RBC models.

A virtue of our model, is that it represents a minimal perturbation of the standard RBC model. This greatly simplifies comparisons with existing work in the literature. However this simplicity is purchased at the cost of descriptive realism. For example, using data from the auto industry, Bresnahan and Ramey (1993) argue that of the multiple margins used by the managers of an automobile assembly plant, varying regular hours by shutting the plant down for a week is the most important. Second most important is adding or dropping a shift. We view the model considered in this paper as approximating these sorts of adjustments. We conjecture that the aggregate capital utilization rate that would 
emerge from explicitly modeling those richer environments would also respond positively to technology shocks and innovation to government purchases. In this sense we expect the qualitative features of our model to be quite robust to alternative ways of modeling variable capital utilization. However the robustness of our quantitative results remains very much an open issue to be addressed in future research.

\section{References}

1. Andrews, Donald W.K. (1991) "Heteroskedasticity and Autocorrelation Consistent Covariance Matrix Estimation," Econometrica, Vol. 59, 817-858.

2. Basu, Susanto (1993) "Procyclical Productivity: Overhead Inputs or Cyclical Utilization," manuscript, University of Michigan.

3. Beveridge, Stephen and Charles R. Nelson (1981) "A New Approach to the Decomposition of Economic Time Series into Permanent and Transitory Components with Particular Attention to Measurement of the 'Business Cycle'," Journal of Monetary Economics, Vol. 7, March, 151-174.

4. Bils, M. and J. Cho (1993) "Cyclical Factor Utilization," Discussion Paper 79, Institute for Empirical Macroeconomics, Federal Reserve Bank of Minneapolis.

5. Brayton, F. and E. Mauskopf (1985) "The MPS Model of the United States Economy," Board of Governors of the Federal Reserve Bank of Minneapolis Working Paper 425.

6. Bresnahan, Timothy F. and Valerie A. Ramey (1993) "Segment Shifts and Capacity Utilization in the U.S. Automobile Industry," American Economic Review, Vol. 83, 213-218.

7. Bureau of Economic Analysis (1993) Fixed Reproducible Tangible Wealth in the United States, 1925-89, Washington D.C.: U.S. Department of Commerce, Economics and Statistics Administration.

8. Burnside, Craig (1993) "Notes on the Linearization and GMM Estimation of Real Business Cycle Models," manuscript, University of Pittsburgh.

9. Burnside, Craig and Martin Eichenbaum (1994) "Small Sample Properties of GMMBased Diagnostic Tests," manuscript, Northwestern University.

10. Burnside, Craig, Martin Eichenbaum and Sergjo Rebelo (1993) "Labor Hoarding and the Business Cycle," Journal of Political Economy, Vol. 101, (April), 245-273.

11. Christiano, Lawrence J. (1988) "Why Does Inventory Investment Fluctuate So Much?," Journal of Monetary Economics, Vol. 21, (March/May), 247-280.

12. Christiano, Lawrence J. and Wouter den Haan (1993) "Small Sample Properties of GMM for Business Cycle Analysis," manuscript, Northwestern University.

13. Christiano, L. and Eichenbaum, M. (1992) "Current Real Business Cycle Theories and Aggregate Labor Market Fluctuations," American Economic Revjew, Vol. 82, (June), 430-450. 
14. Cochrane, John (1994) "Shocks," manuscript, University of Chicago.

15. Cogley, James and Timothy Nason (1993) "Do Real Business Cycles Models Pass the Nelson-Plosser Test?" manuscript, University of British Columbia.

16. Finn, Mary (1991) "Energy Price Shocks, Capacity Utilization and Business Cycle Fluctuations," Discussion Paper No. 50, Institute for Empirical Economics, Federal Reserve Bank of Minneapolis.

17. Gordon, Robert J. (1990) “Are Procyclical Productivity Fluctuations A Figment of Measurement Error," manuscript, Northwestern University.

18. Greenwood, Jeremy, Zvi Hercowitz and Gregory W. Huffman (1988) "Investment, Capacity Utilization and the Real Business Cycle," American Economic Review, Vol. 78, (June), 402-417.

19. Greenwood, Jeremy, Zvi Hercowitz and Per Krussel (1992) "Macroeconomic Implications of Investment-Specific Technological Change," Institute for International Economic Studies, Seminar Paper No. 527.

20. Hansen, Gary D. (1985) "Indivisible Labor and the Business Cycle," Journal of Monetary Economics, Vol. 16, (November), 309-328.

21. Hansen, Lars P. (1982) "Large Sample Properties of Generalized Method of Moments Estimators," Econometrica, Vol. 50, 1029-1054.

22. Hodrick, Robert J. and Edward C. Prescott (1980) "Post-War Business Cycle: An Empirical Investigation," manuscript, Carnegie Mellon University.

23. King, Robert G. and Sergio Rebelo (1993a) "Transitional Dynamics and Economic Growth in the Neoclassical Model," American Economic Review, Vol. 83, (September), 908-931.

24. King, Robert G. and Sergio Rebelo (1993b) "Low Frequency Filtering and Real Business Cycles," Journal of Economic Dynamics and Control, Vol.17 (January/March), 207-231.

25. King, Robert G., Charles I. Plosser and Sergio Rebelo (1988) "Production, Growth and Business Cycles," Journal of Monetary Economics, Vol. 21, (March/May) 195232.

26. King, Robert G. and Mark W. Watson (1993) "Diagnosing Business Cycle Models," manuscript, Northwestern University.

27. Kydland, Finn and Edward C. Prescott (1988) "The Workweek of Capital and its Cyclical Implications," Journal of Monetary Economics, Vol. 21, (March/May), 343-360.

28. Newey, Whitney and Kenneth West (1987) "A Simple, Positive Semi-definite, Heteroskedasticity and Autocorrelation Consistent Covariance Matrix," Econometrica, Vol. 55, 703-708.

29. Prescott, Edward C. (1986) "Theory Ahead of Business Cycle Measurement," Federal Reserve Bank of Minneapolis Quarterly Review, Vol. 10, Fall. 
30. Rotemberg, Julio J. and Lawrence H. Summers (1990) "Inflexible Prices and Procyclical Productivity," Quarterly Journal of Economics, Vol. 105, November, 851874.

31. Rotemberg, Julio J. and Michael Woodford (1994) "Can Stochastic Technical Progress Explain the Forecastable Movements in GNP?" manuscript, University of Chicago.

32. Sbordone, Argia (1993) "A Dynamic Model of Labor Hoarding," manuscript, Federal Reserve Bank of Chicago.

33. Shapiro, Matthew D. (1989) "Assessing the Federal Reserve's Measures of Capacity and Utilization," Brookings Papers on Economic Activity, No. 1, 181-225.

34. Shapiro, Matthew D. (1993) "Cyclical Productivity and the Work Week of Capital," American Economic Review, Vol. 83, (May), 229-233.

35. Watson, Mark W. (1993) "Measures of Fit for Calibrated Models," Journal of Political Economy, Vol. 101, (December), 1011-1041. 
TABLE 1

Model Parameters $\boldsymbol{\Psi}$

Estimates and Standard Errors*

\begin{tabular}{|l|cc|cc|}
\hline & \multicolumn{2}{|c|}{ Benchmark Model } & \multicolumn{2}{c|}{ Factor Hoarding Model } \\
\hline Parameter & Estimate & Std. Error & Estimate & Std. Error \\
\hline$\theta$ & 5.1199 & $(0.0577)$ & 3.5955 & $(0.0440)$ \\
$\alpha$ & 0.6553 & $(0.0062)$ & 0.6422 & $(0.0225)$ \\
$\vec{\delta}$ & 0.0208 & $(0.0002)$ & 0.0208 & $(0.0003)$ \\
$\gamma$ & 0.0031 & $(0.0018)$ & 0.0038 & $(0.0014)$ \\
$\sigma_{v}$ & 0.0135 & $(0.0014)$ & 0.0088 & $(0.0008)$ \\
$g / y$ & 0.1763 & $(0.0024)$ & 0.1763 & $(0.0025)$ \\
$g_{0}$ & -1.8753 & $(0.0366)$ & 1.7885 & $(0.0943)$ \\
$g_{1}$ & -0.0013 & $(0.0002)$ & -0.0019 & $(0.0003)$ \\
$\rho$ & 0.9150 & $(0.0453)$ & 0.9456 & $(0.0349)$ \\
$\sigma_{c}$ & 0.0163 & $(0.0014)$ & 0.0152 & $(0.0014)$ \\
$\sigma_{\xi}$ & 0.0088 & $(0.0012)$ & 0.0088 & $(0.0012)$ \\
\hline$B_{T}$ & \multicolumn{2}{|c|}{2.51} & \multicolumn{2}{c|}{2.77} \\
\hline \hline
\end{tabular}

- All standard errors shown in this table are based on estimates of $S_{T}$ computed using the Bartlett window suggested by Newey and West (1987). The row $B_{T}$ indicates the bandwidth of the lag window used to estimate $S_{T}$ as chosen by the automated procedure described in the text. 
TABLE 2

Tests of the Models.

\begin{tabular}{|l|ccc|}
\hline \hline Moment & U.S. Data & $\begin{array}{c}\text { Benchmark } \\
\text { Model }\end{array}$ & $\begin{array}{c}\text { Factor Hoarding } \\
\text { Model }\end{array}$ \\
\hline$\sigma_{c} / \sigma_{y}$ & 0.437 & 0.453 & 0.480 \\
& $(0.034)$ & $(0.005)$ & $(0.010)$ \\
& & {$[0.633]$} & {$[0.225]$} \\
\hline$\sigma_{i} / \sigma_{\nu}$ & 2.224 & 2.224 & 2.244 \\
& $(0.079)$ & $(0.069)$ & $(0.085)$ \\
& & {$[0.999]$} & {$[0.858]$} \\
\hline$\sigma_{\Lambda} / \sigma_{\nu}$ & 0.859 & 0.757 & 0.795 \\
& $(0.080)$ & $(0.050)$ & $(0.059)$ \\
& & {$[0.183]$} & {$[0.394]$} \\
\hline$\sigma_{\Lambda} / \sigma_{\text {apt }}$ & 1.221 & 1.171 & 1.033 \\
& $(0.132)$ & $(0.032)$ & $(0.043)$ \\
& & $0.729]$ & {$[0.198]$} \\
\hline \hline
\end{tabular}

TABLE 3

Propagation and the Volatility of Output*

\begin{tabular}{|l|ccc|cc|}
\hline \hline Model & $\sigma_{y}$ (Model) & $\sigma_{y}$ (Data) & $W$ & $\sigma_{z}$ & $\sigma_{y} / \sigma_{z}$ \\
\hline Benchmark & 0.0183 & 0.0192 & 0.137 & 0.0174 & 1.051 \\
& $(0.0019)$ & $(0.0021)$ & $0.712]$ & $(0.0018)$ & $(0.014)$ \\
Labor Hoarding & 0.0157 & 0.0192 & 2.951 & 0.0155 & 1.011 \\
& $(0.0012)$ & $(0.0021)$ & $0.086]$ & $(0.0013)$ & $(0.014)$ \\
Factor Hoarding & 0.0167 & 0.0192 & 1.185 & 0.0114 & 1.467 \\
& $(0.0015)$ & $(0.0021)$ & 0.276 & $(0.0010)$ & $(0.031)$ \\
\hline \hline
\end{tabular}

-The statistic $\sigma_{4}$ is the standard deviation of HP filtered output. The statistic $\sigma_{z}$ is the standard deviation of the HP filtered level of technology. Standard errors of the statistics are in parentheses. $W$ statistics are for tests of the hypothesis $\sigma_{v}$ (Model) $=\sigma_{\nu}$ (Data). $P$-values are in brackets. 
FIGURE 1

MEASURes OF CAPITAL AND UTILIZATION*

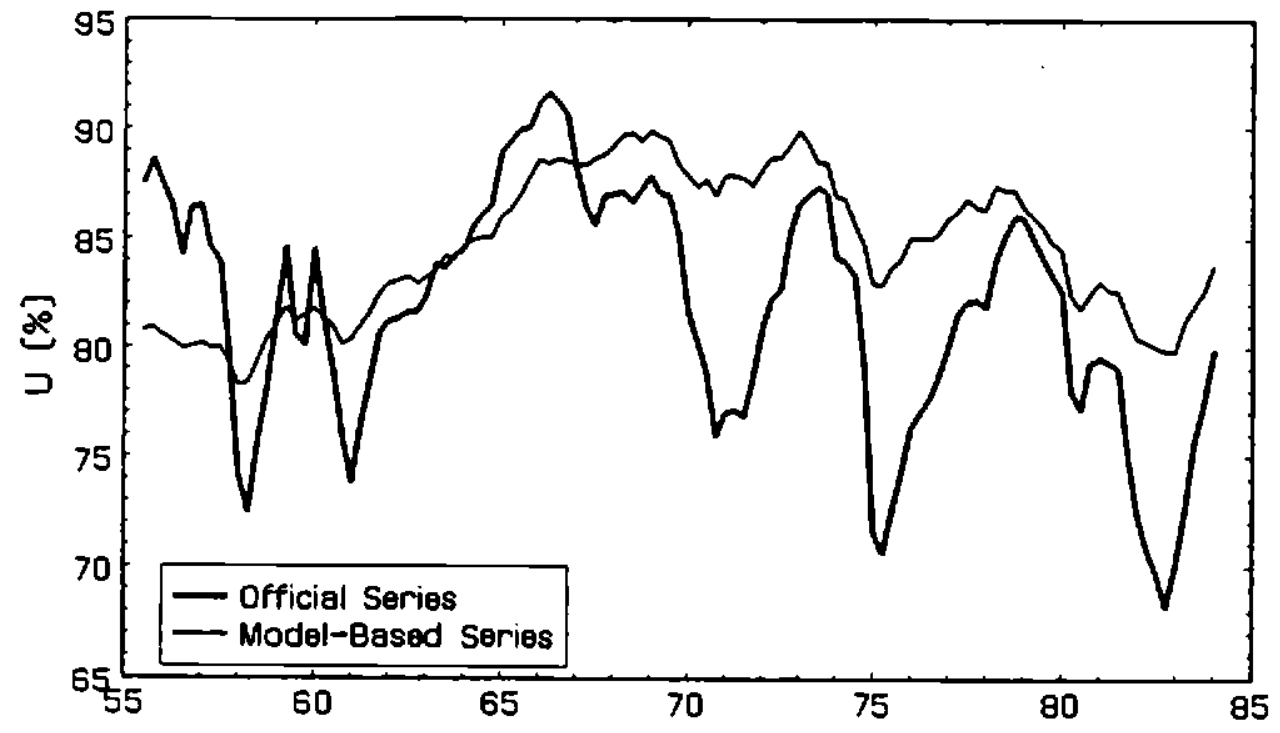

- The thick line is the Federal Reserve's measure of capacity utilization in the manufacturing sector. The thin line is our measure of capital utilization. 
FIGURE 2

CoRrelation of $A P L_{i}$ WITH $H_{i+i}$ (HP FILTER)
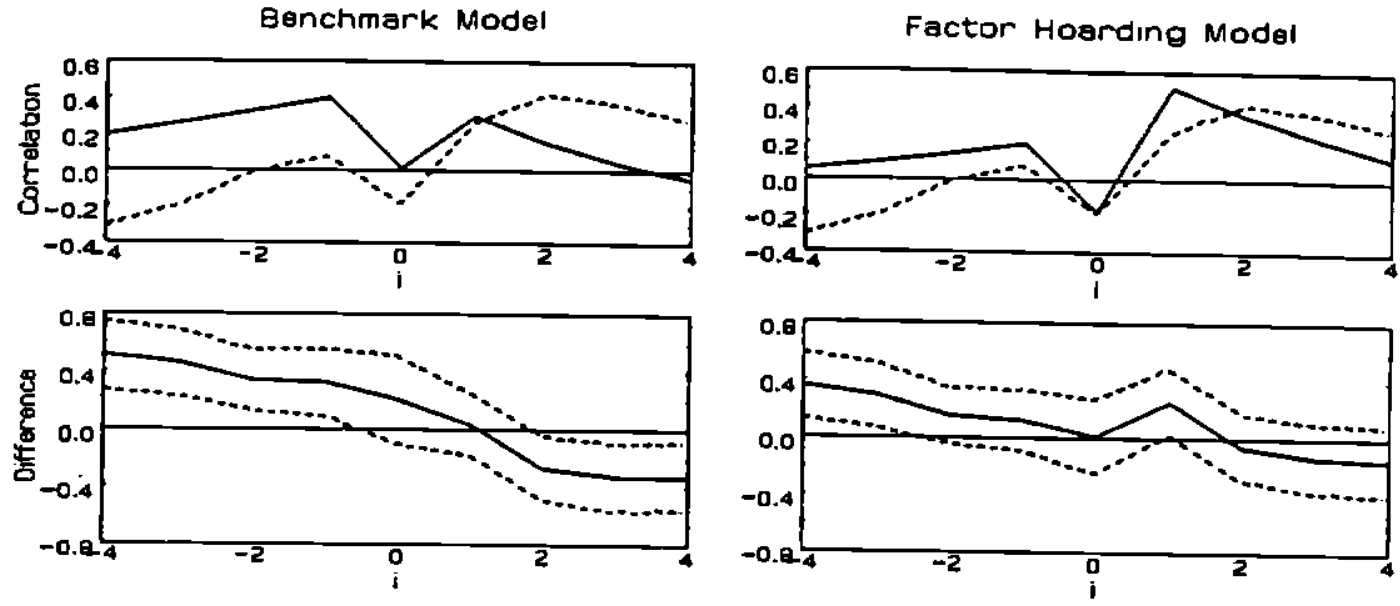

FIGURE 3

CoRrelation of $A P L_{t}$ WITH $Y_{t+i}$ (HP Filter)
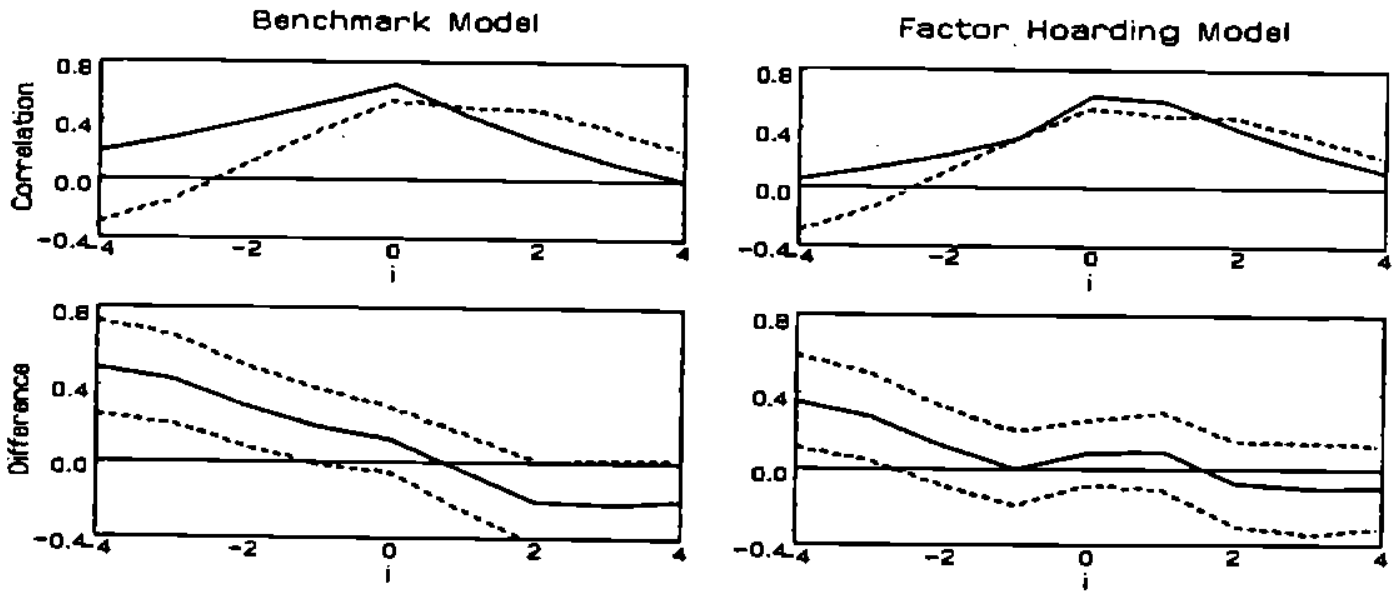

-In the Correlation panels: solid line - model predicted correlations, dashed line - sample correlations. In the Difference panels the dashed lines represent a 2-standard error band around the difference. 
FIGURE 4

IMPULSE RESPONSE FUNCTION OF OUTPUT'

Benchmark Model
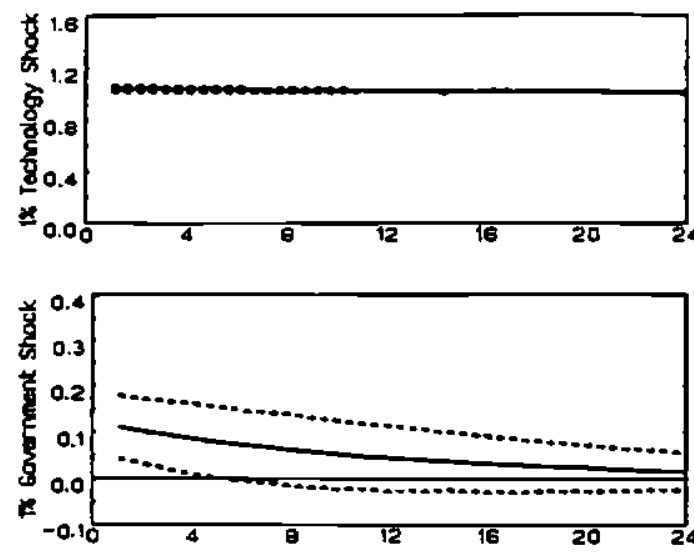

FIGURE 5

IMPULSE RESPONSE FUNCTION OF HOURS•
Factor Hoarding Madel
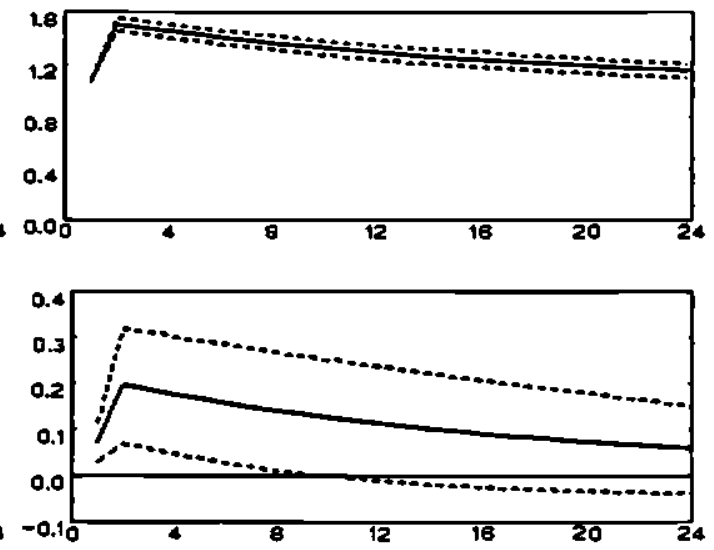
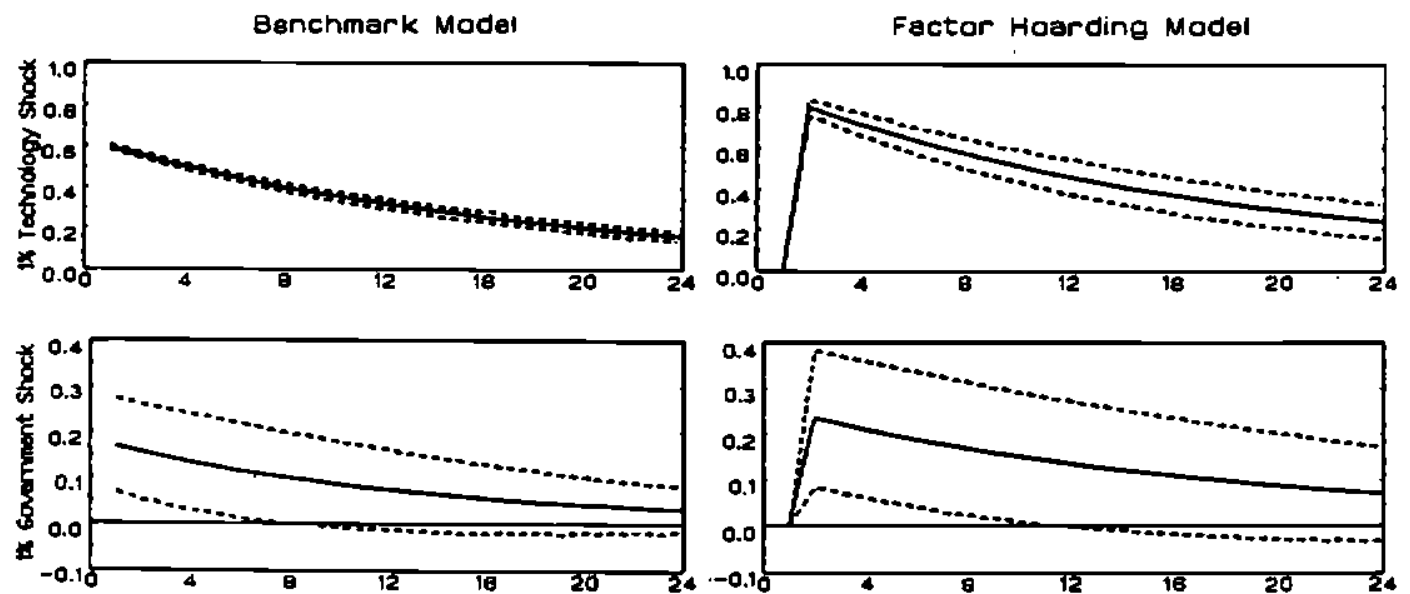

"The dashed lines represent a 2-standard error band around the impulse response functions due to parameter uncertainty. 


\section{FIGURE 6}

IMPULSE RESPONSE FUNCTIONS - FACTOR HOARDING MODEL'
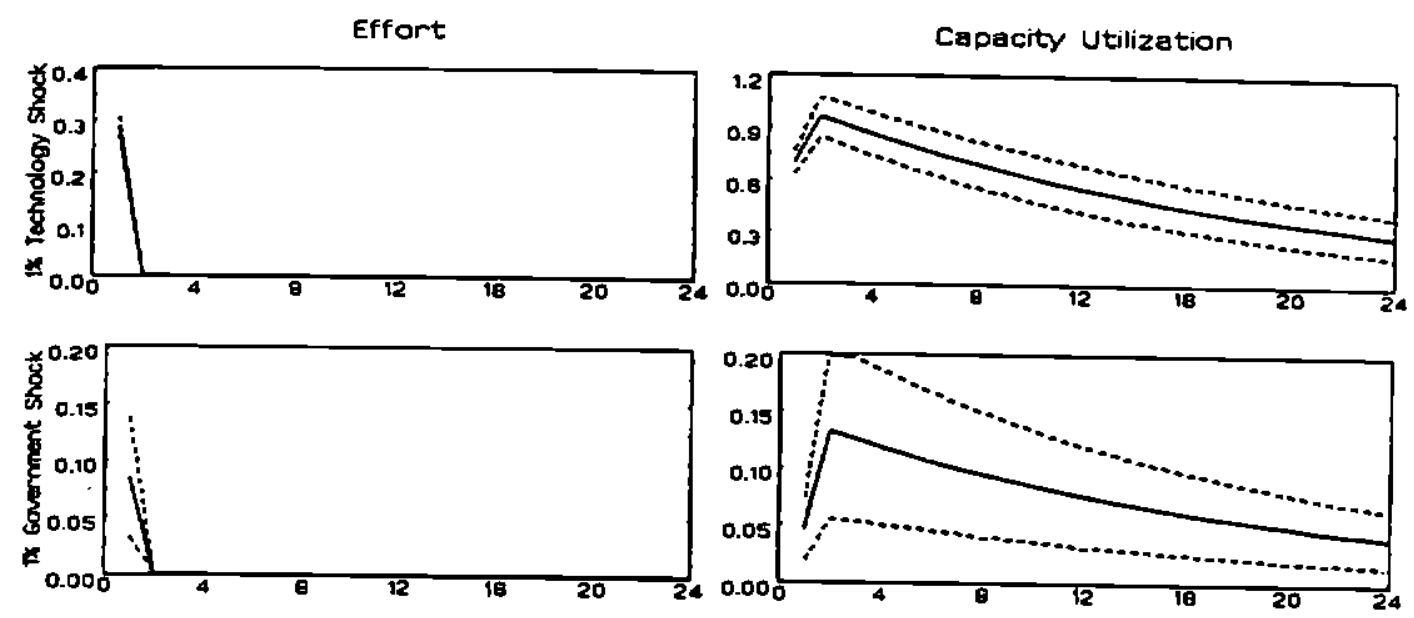

FIGURE 7

IMPULSE RESPONSE FUNCTION OF CONSUMPTION
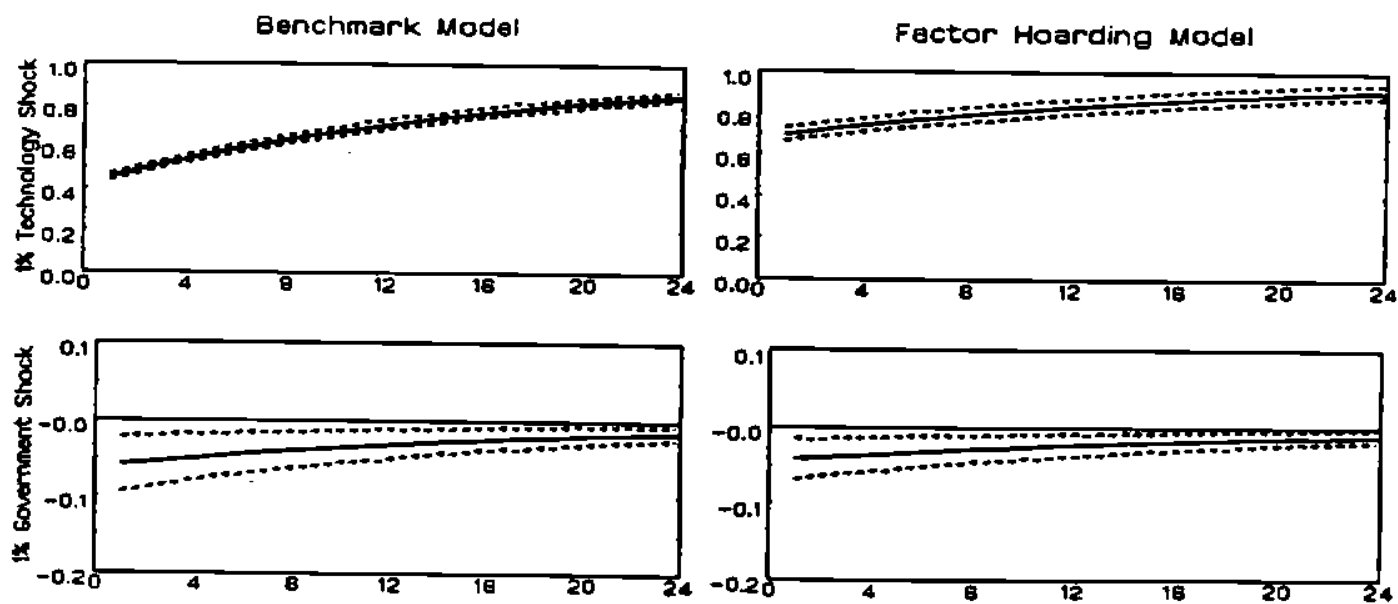
-The dashed lines represent a 2 -standard error band around the impulse response functions
due to parameter uncertainty. 
FIGURE 8

IMPULSE RESPONSE FUNCTION OF INVESTMENT*
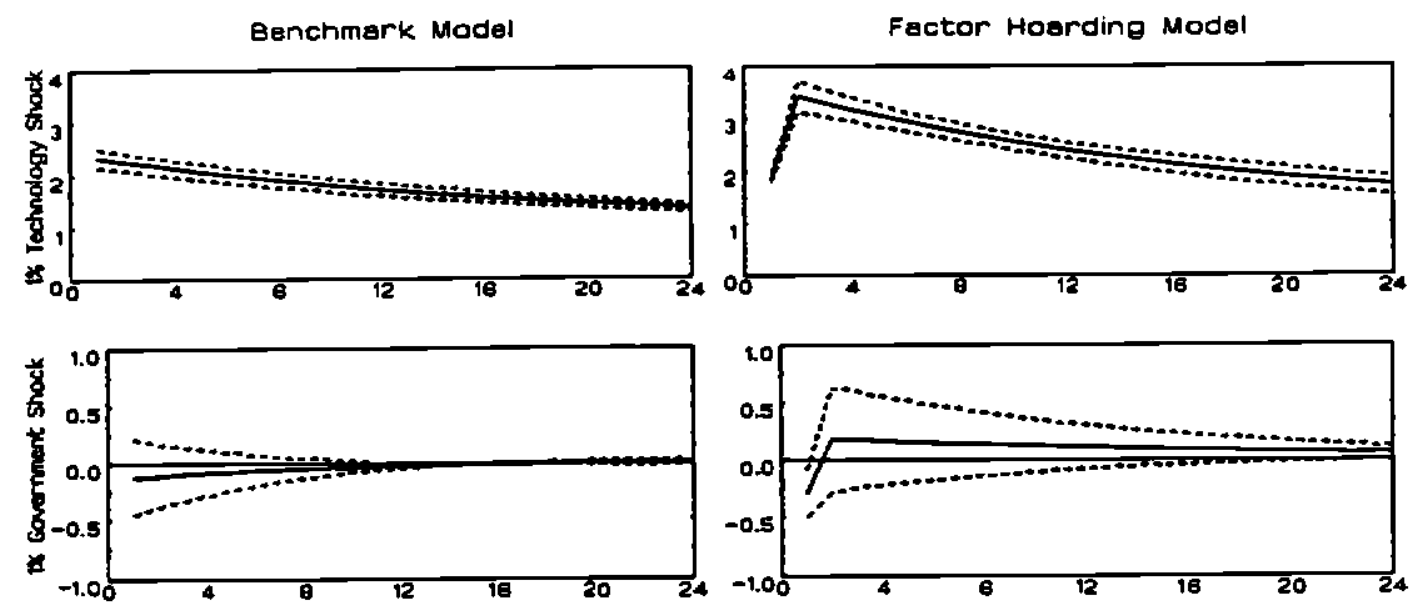

FIGURE 9

IMPULSE RESPONSE FUNCTIONS - FACTOR HOARDING MODEL"

Average Productivity
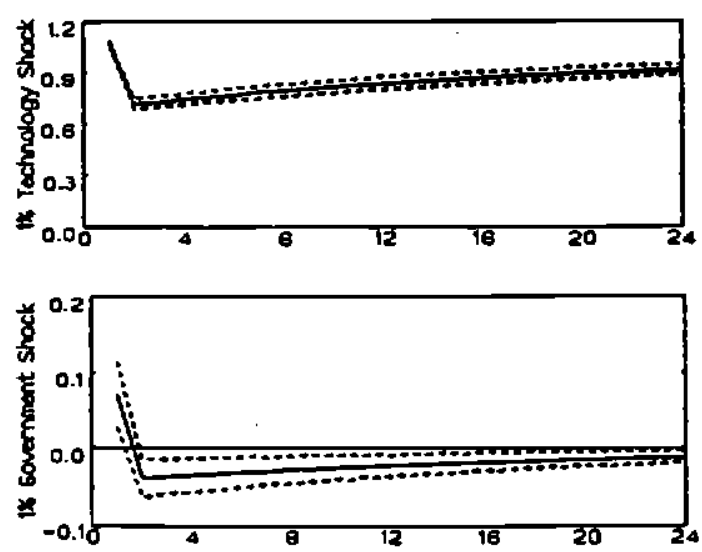

Solow Aesidual
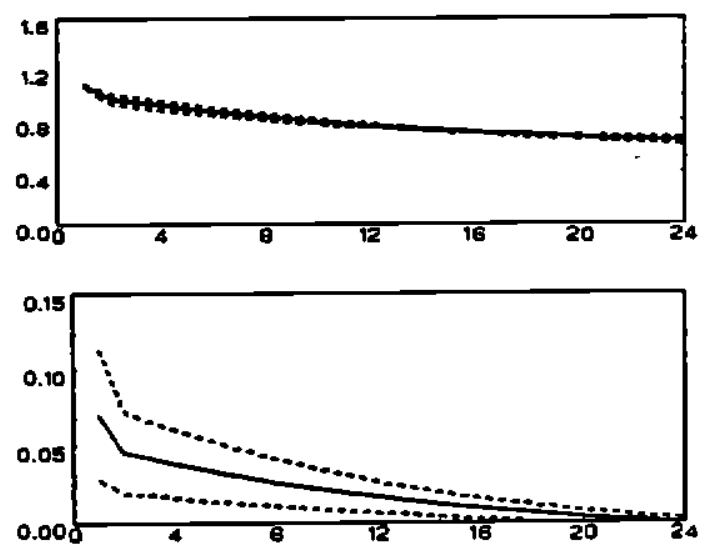

-The dashed lines represent a 2-standard error band around the impulse response functions due to parameter uncertainty. 

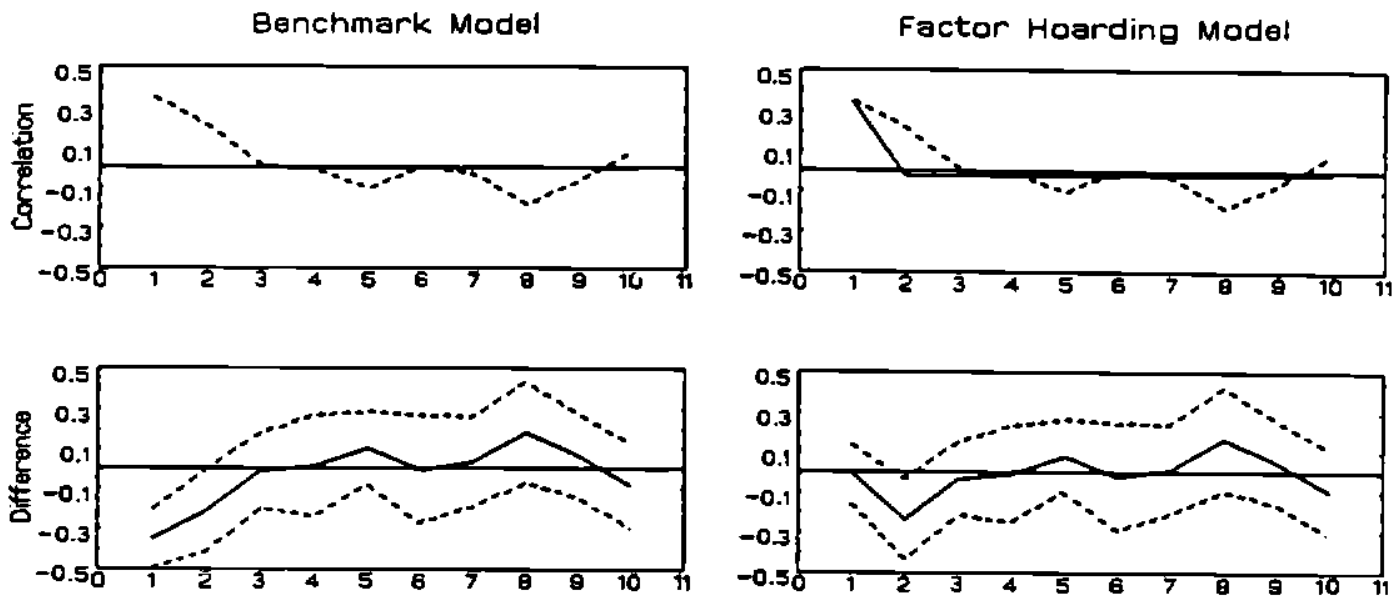

FIGURE 11

AUtOCORRELATIONS OF THE SOLOW RESIDUAL"
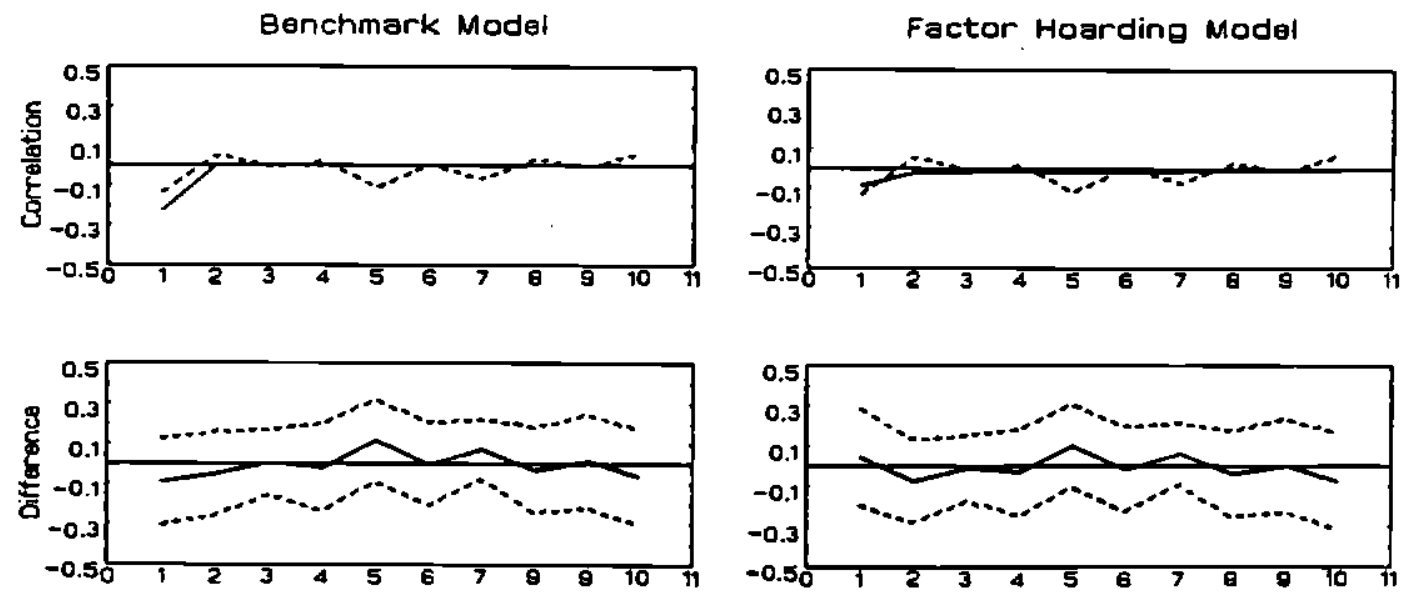

'In the Correlation panels: solid line - model predicted correlations, dashed line - sample correlations. In the Difference panels the dashed lines represent a 2-8tandard error band around the difference. 
FIGURE 12

THE SPECTRUM OF OUTPUT GROWTH*

Benchmark Model

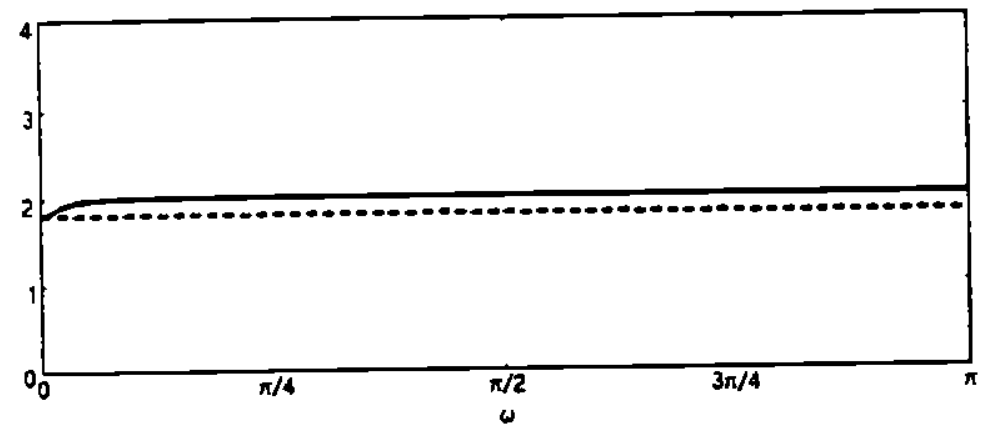

Factor Hoarding Model

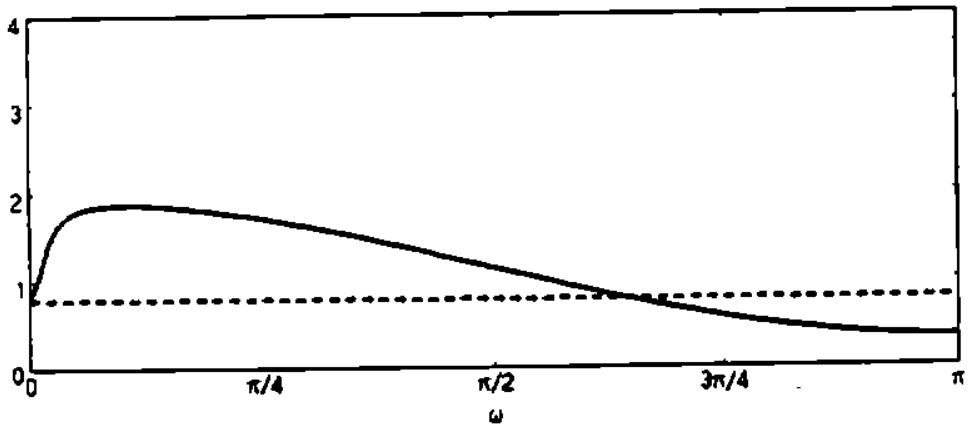

US Data 5503-8401

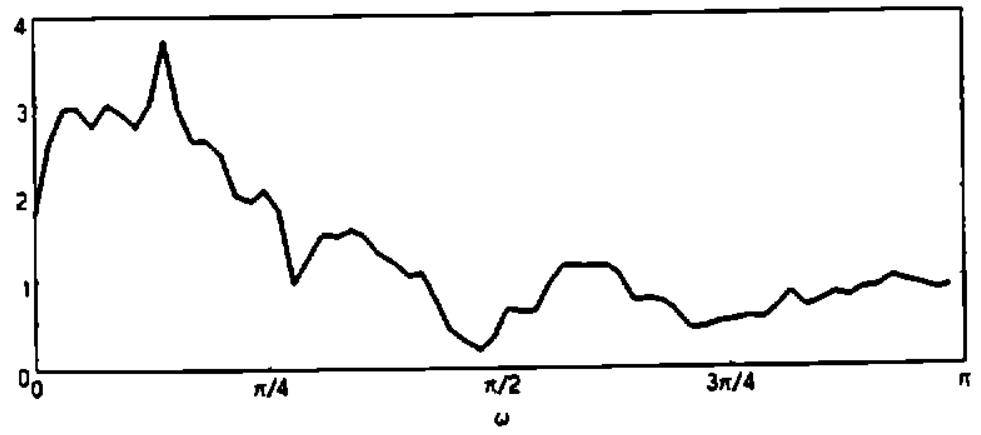

-The solid line represents the spectrum of output growth, while the dashed line represents the spectrum of technology shocks. The spectrum for U.S. data was computed using the RATS 4.0 example program SPECTRUM.SRC. 
FIGURE 13

MOMENTS OF PREDICTED GROWTH IN OUTPUT, HOURS AND PRODUCTIVITY*

Moment
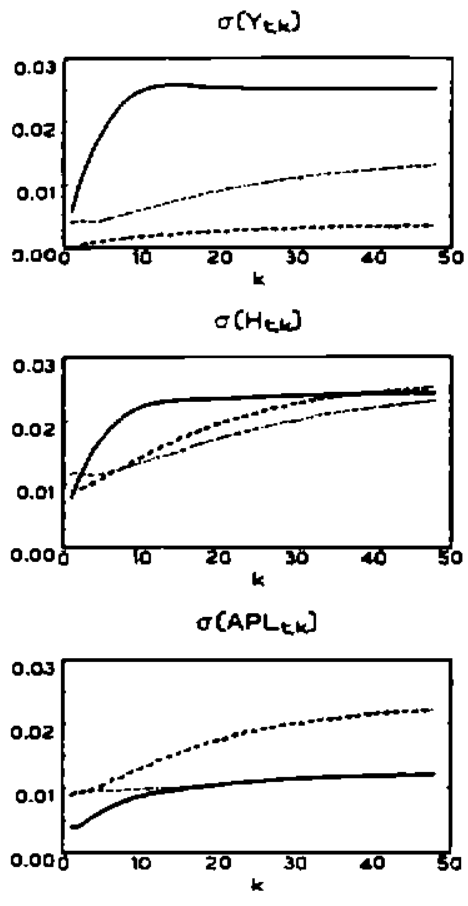

$o\left(r_{t k}, M_{t w}\right.$

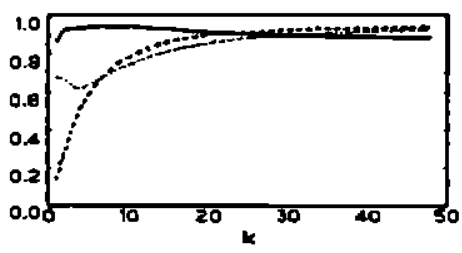

$\rho\left(Y_{\text {tK }}\right.$. APLEK)

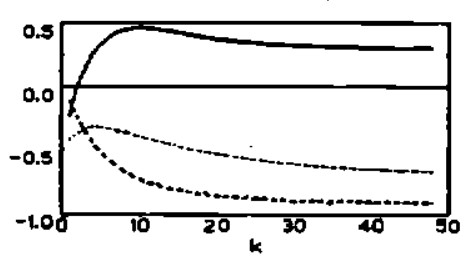

\section{Difference}

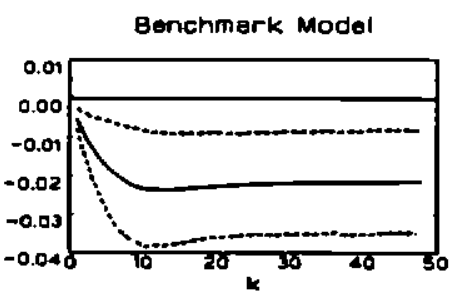

Benchmerk Model

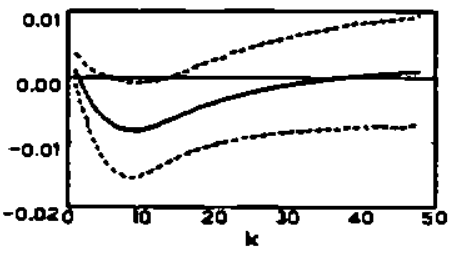

Benchmerk Model

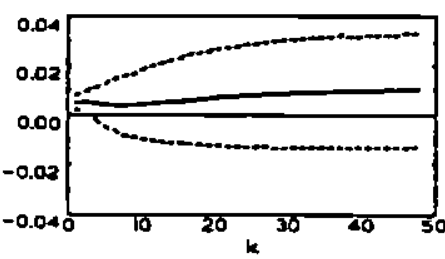

Benchmerk Model

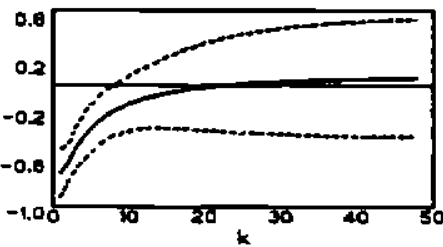

Benchmark Model

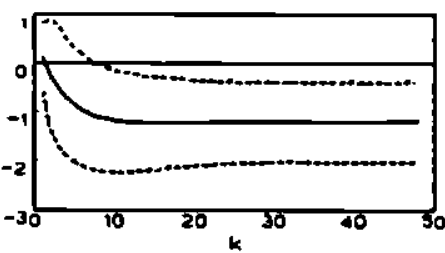

Factor Moarding Model

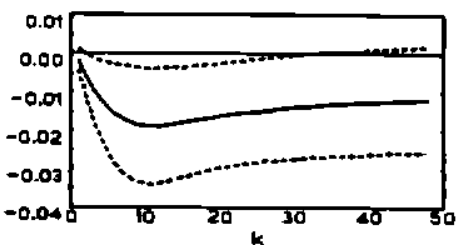

Factor Hourding Model

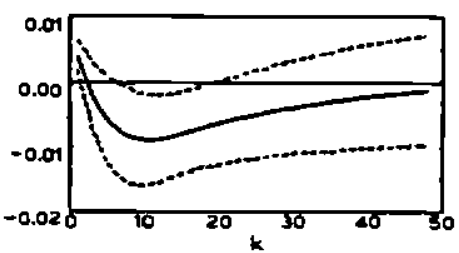

Fector Moarding Model

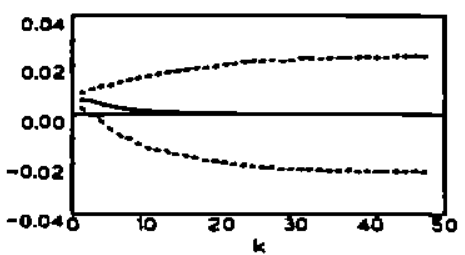

Fector Mosrding Madel

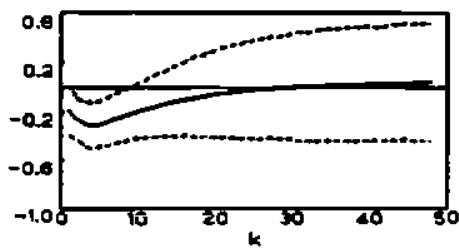

Factor Moarding Model

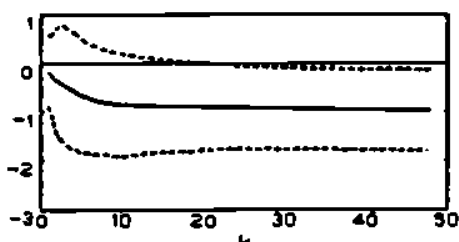

-In the Moment column: solid line - sample moment, dashed line - prediction of benchmark model, dotted line - prediction of factor hoarding model. In the Difference column the dashed lines represent a 2-8tandard error band around the difference. 
FIGURE 14

Correlations of PREdicted Growth in OUTPUT with Macro Tme Series*

Correlation

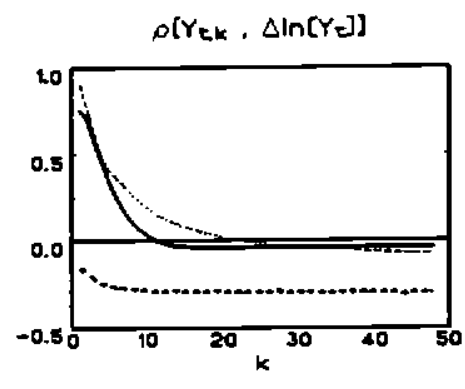

$o\left[r e k, \ln \left[C_{0}\right)\right]$

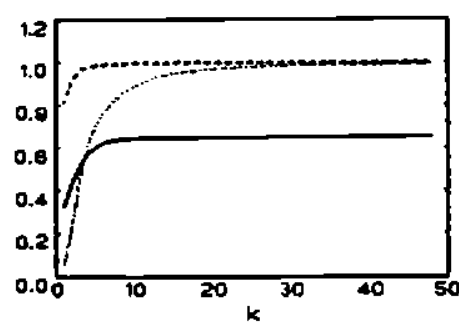

$\rho\left[\gamma_{\tau, k}, \ln \left[\mathrm{H}_{\tau}\right]\right]$

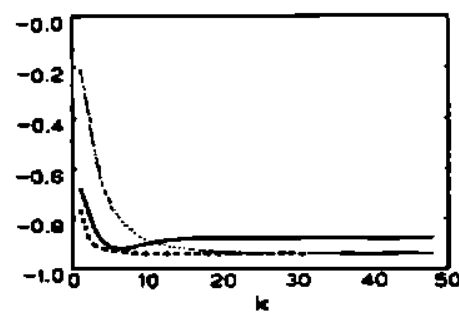

$o[Y=X, \triangle I n[A P L E]]$

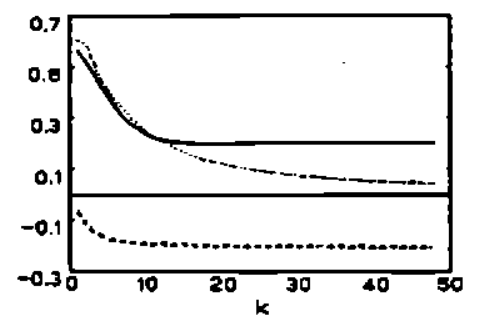

Difference

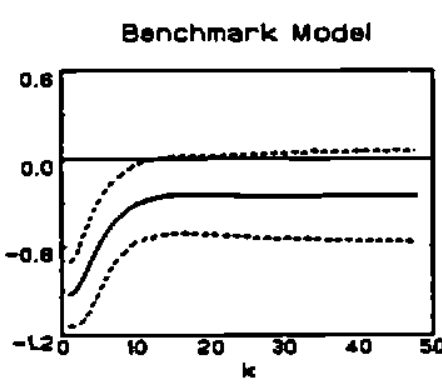

Benchmerk Model

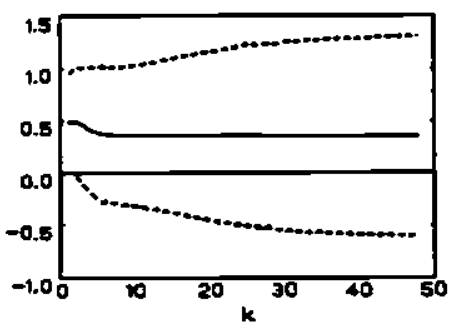

Bonchmark Model

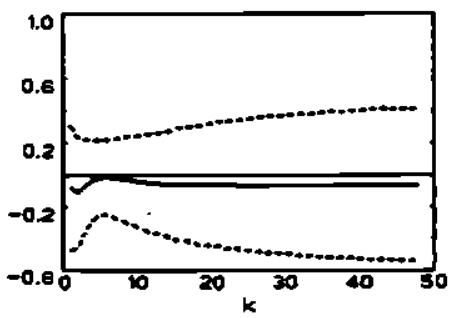

Benchmark Model

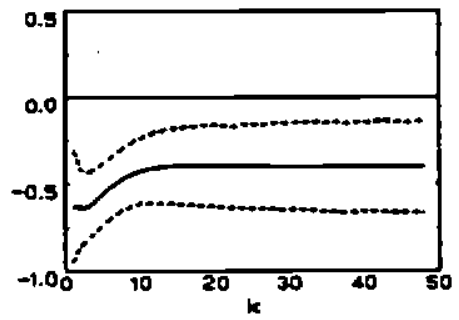

Factor Hoarding Model

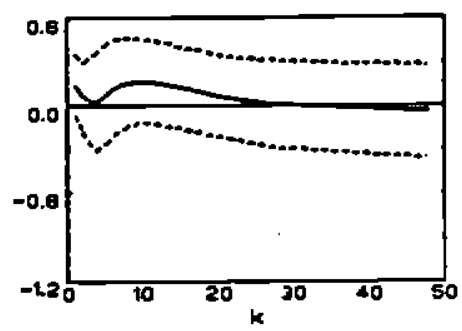

Foctor Hoording Model

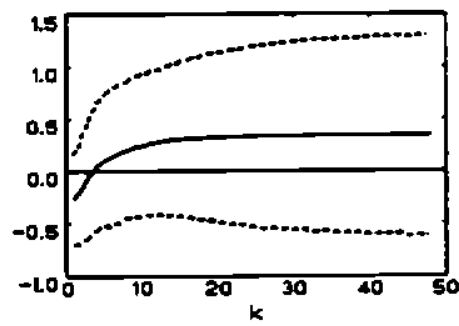

Factor Hoarding Model

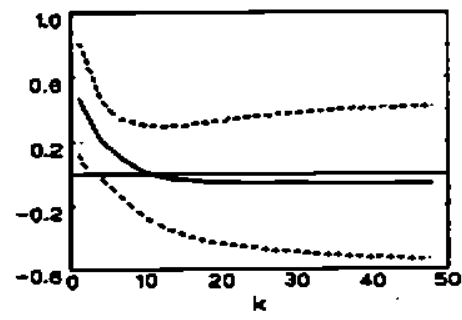

Factor Hoerding Model

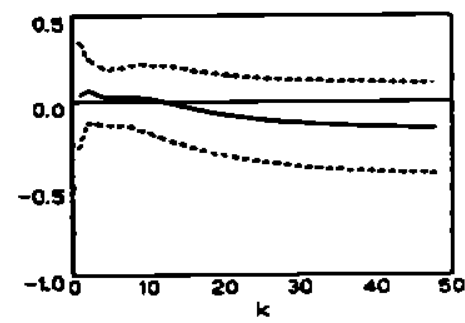

-In the Correlation column: solid line - sample correlation, dashed line - prediction of benchmark model, dotted line - prediction of factor hoarding model. In the Difference column the dashed lines represent a 2-standard error band around the difference. 


\section{Appendix}

\section{A.1 A Note on Steady State Conditions in the Factor Hoarding Model}

In this section we show that the parameter $\phi$ is restricted by the nonstochastic steady state conditions from the factor hoarding model. Furthermore, since the linearized model does not depend on us being able to separately identify the values of $\delta$ and the nonstochastic steady state value of capital utilization, denoted $U$, we only estimate the nonstochastic steady state value of depreciation, $\delta=\delta U^{\dagger}$. Take the planner's Euler equations for utilization and the next period's capital stock. These are, respectively,

$$
\begin{aligned}
(1-\alpha) \frac{Y_{t}}{U_{t}} & =\phi \delta U_{t}^{t-1} K_{t} \\
C_{t}^{-1} & =\beta E_{t} C_{t+1}^{-1}\left[(1-\alpha) \frac{Y_{t+1}}{K_{t+1}}+\left(1-\delta_{t+1}\right)\right] .
\end{aligned}
$$

Given that $\delta_{t}=\delta U_{i}^{*}$, it follows that the nonstochastic steady state value of $\delta_{t}$, which we denote $\vec{\delta}$ is equal to $\delta U^{*}$, where $U$ is the nonstochastic steady state value of $U_{t}$. Rewrite (A.2) as

$$
\left.1=\beta E_{t} \frac{C_{t}}{X_{t}} \frac{X_{t+1}}{C_{t+1}}\left[(1-\alpha) \frac{Y_{t+1}}{X_{t+1}} \frac{X_{t}}{K_{t+1}}+\left(1-\delta_{t+1}\right) \frac{X_{t}}{X_{t+1}}\right)\right] .
$$

Denote the nonstochastic steady state value of $Y_{t} / X_{t}$ and $K_{t} / X_{t-1}$ as $y$ and $k$ respectively. Then, in the nonstochastic steady state (A.2) is given by

$$
1=\beta\left[(1-\alpha) \frac{y}{k}+(1-\bar{\delta}) \exp (-\gamma)\right] .
$$

This can be solved for the output-capital ratio

$$
\frac{y}{k}=\frac{\beta^{-1}-(1-\bar{\delta}) \exp (-\gamma)}{1-\alpha} .
$$

Notice that (A.1) can be rearranged as $(1-\alpha) Y_{1} / K_{t}=\phi \delta U_{l}^{*}$. This implies that in the nonstochastic steady state

$$
(1-\alpha) \frac{y}{k} \exp (\gamma)=\phi \delta U^{\phi}=\phi \bar{\delta} .
$$

Substituting (A.5) into (A.6) and solving for $\phi$ we have

$$
\phi=\frac{\beta^{-1} \exp (\gamma)-1}{\delta}+1
$$

Therefore, given values of $\beta, \gamma$ and $\delta$ the parameter $\phi$ need not be treated as a free parameter. We estimate $\bar{\delta}$ by matching its logarithm to the mean of the logarithm of our official depreciation series. This implies a value of $\phi$. The reader may refer to Burnside (1993) to see that in order to compute the coefficients in the linearized model we never require specific values of $\delta$ and $U$. 


\section{A.2 Measuring Capital, Depreciation, Utilization, Effort and Technology}

In this section we describe how we can measure various series given a vector of model parameters, $\Psi_{1}$. In the next section we describe our scheme for identifying $\Psi_{1}$. The first measure of capital we have is the official series $\tilde{K}_{t}$. We treat this as an imperfect measure of the true capital stock. Our first (imperfect) measure of the depreciation rate is $\tilde{\delta}_{t}=1+\left(I_{t}-\tilde{K}_{t+1}\right) / \tilde{K}_{t}$. Given values of the parameters $\bar{\delta}, \beta$ and $\gamma$ and $\alpha$ we recursively generate time series on $\delta_{t}$ and $K_{t}$. We parameterize the ratio of the initial true capital stock to the initial official capital stock by defining, $A_{k} \equiv K_{1} / \tilde{K}_{1}$. Our recursive procedure exploits the progression

$$
\begin{aligned}
K_{1} & =A_{k} \bar{K}_{1} \\
\delta_{1} & =(1-\alpha) Y_{1} /\left(\phi K_{1}\right) \\
K_{2} & =\left(1-\delta_{1}\right) K_{1}+I_{1} \\
\delta_{2} & =(1-\alpha) Y_{2} /\left(\phi K_{2}\right) \\
& \cdots \\
\delta_{T} & =(1-\alpha) Y_{T} /\left(\phi K_{T}\right) .
\end{aligned}
$$

The value of $\phi$ is determined by the values of $\delta, \beta$ and $\gamma$ according to (19).

The only purpose for which we need a series on utilization is in order to create Figure 1. For this purpose we chose $\delta=0.0285$, and used the relationship $U_{t}=\left(\delta_{t} / \delta\right)^{1 / \phi}$. However, we do not estimate $\delta$ so it is not included in our specification of $\Psi_{1}$.

The variable $W_{t}$ is not observable, nor is the level of technology $X_{t}$. However, as described in section 3 , we can construct measures of these variables using the decision rule for the log of effort, $w_{i}$, and using the form of the production function. The decision rule for effort is

$$
w_{t}=\kappa_{0}+\kappa_{1} k_{t}+\kappa_{3} n_{t}+\kappa_{3} v_{t}+\kappa_{4} g_{t},
$$

where the vector of coefficients $x$ depends on the parameters of the model. Notice that

$$
\begin{array}{r}
w_{t}=\kappa_{0}+\kappa_{1}\left[\ln \left(K_{t}\right)-\ln \left(X_{t-1}\right)\right]+\kappa_{2}\left[\ln \left(H_{t}^{*}\right)-\ln (f)\right]+ \\
\kappa_{3}\left[\ln \left(X_{t}\right)-\ln \left(X_{t-1}\right)-\gamma\right]+\kappa_{t}\left[\ln \left(G_{t}\right)-\ln \left(X_{t}\right)\right] .
\end{array}
$$

Here we use the notation $\ln \left(H_{t}^{*}\right)$ to refer to true hours worked. In the next section we adjust our analysis to take into account the effects of measurement error.

An artifact of the model is that $\kappa_{1}=-\kappa_{3}$. Therefore, for some constant $\pi_{0}$ the decision rule for effort implies that

$$
\ln \left(W_{t}\right)=\pi_{0}+\pi_{1} \ln \left(K_{t}\right)+\pi_{3} \ln \left(H_{t}^{*}\right)+\pi_{3} \ln \left(G_{1}\right)+\pi_{t} \ln \left(X_{t}\right),
$$

where $\pi_{1}=\kappa_{1}, \pi_{2}=\kappa_{2}, \pi_{3}=x_{4}$ and $\pi_{4}=\kappa_{3}-\kappa_{4}$.

The production function implies that

$$
\ln \left(Y_{t}\right)=(1-\alpha) \ln \left(K_{t}\right)+(1-\alpha) \ln \left(U_{1}\right)+\alpha \ln \left(H_{i}^{*}\right)+\alpha \ln \left(W_{t}\right)+\alpha \ln \left(X_{t}\right)
$$

Substituting in the expression for $\ln \left(W_{t}\right)$ and noting that $\ln \left(U_{t}\right)=\phi^{-1}\left[\ln \left(\delta_{t}\right)-\ln (\delta)\right]=$ $\phi^{-1}\left(\ln (1-\alpha)-\ln (\phi)+\ln \left(Y_{t}\right)-\ln \left(K_{t}\right)\right)$, and solving for the value of $\ln \left(X_{t}\right)$ we see that

$$
\ln \left(X_{i}\right)=\varphi_{0}+\varphi_{1} \ln \left(Y_{i}\right)+\varphi_{2} \ln \left(K_{i}\right)+\varphi_{3} \ln \left(H_{i}^{*}\right)+\varphi_{i} \ln \left(G_{i}\right)
$$


where

$$
\begin{aligned}
& \varphi_{1}=-\left[(1-\alpha) \phi^{-1} / \alpha-\alpha^{-1}\right] /\left(1+\pi_{1}\right) \\
& \varphi_{2}=-\left[(1-\alpha)\left(1-\phi^{-1}\right) / \alpha+\pi_{1}\right] /\left(1+\pi_{1}\right) \\
& \varphi_{3}=-\left(1+\pi_{2}\right) /\left(1+\pi_{1}\right) \\
& \varphi_{1}=-\pi_{3} /\left(1+\pi_{1}\right),
\end{aligned}
$$

and $\varphi_{0}$ is some constant which depends on $\Psi_{1}$. Given the values of $X_{t},(A .8)$ can be used to determine $W_{t}$.

\section{A.3 The Moment Restrictions Underlying the GMM Estimator}

This section describes our method for estimating the parameter vector $\Psi$. We use an exactly identified GMM (Hansen 1982) estimator as in Christiano and Eichenbaum (1992) and Burnside, Eichenbaum and Rebelo (1993). In the previous section we described our method for measuring effort, utilization, capital and the level of technology given a vector of parameters. In this section we describe moment restrictions which enable us to identify these parameters.

As in the latter two papers we assume that the measures of hours worked available to us are measured with error. In our model the true measure of hours is defined as $H_{i}^{*}=N_{t} f$, the number of workers employed times the fixed shift length. The two measures of hours we have are Hansen's (1985) hours series based on the household survey, denoted $H_{1}$, and a measure of hours based on the establishment survey, denoted $\tilde{H}_{t}$. We assume that in logarithms each of these deviates from the true level of hours worked according to independent white noise processes, $\xi_{t}$ and $\tilde{\xi}_{t}$, with standard deviations $\sigma_{\xi}$ and $\tilde{\sigma}_{\xi}$ respectively. The primary hours series we use is the household series. In order to obtain an estimate of the standard deviation of the measurement error in this series we use the following identifying restriction,

$$
E\left\{\sigma_{\xi}^{2}-\frac{1}{2}\left[\Delta \ln \left(H_{t}\right)\right]^{2}+\frac{1}{2} \Delta \ln \left(H_{t}\right) \Delta \ln \left(\bar{H}_{t}\right)\right\}=0 .
$$

We fix the parameters $\beta=1.03^{-1 / 4}, T=1369$ and $\zeta=60$ as in Burnside, Eichenbaum and Rebelo (1993). Furthermore, $f$ is chosen in order to normalize the nonstochastic steady state value of effort to 1 . The remaining parameters to be estimated are $\theta, \alpha, \delta$, $\gamma, \sigma_{v},(g / y), g_{0}, g_{1}, \rho, \sigma_{e}$ and $A_{k}$. Measurement error in hours worked forces us to adjust several of the natural restrictions that would identify these parameters.

The nonstochastic steady state level of employment $N$ is implicitly a function of $\Psi_{1}$. Therefore, we use the following restriction implied by the model

$$
E\left[\ln \left(H_{1}\right)-\ln (N \rho)\right]=0 .
$$

Note that measurement error in hours worked does not change the mean of the log of hours. 
We assume that the official capital series, while not capturing variations in capital utilization, leads to the correct depreciation rates on average. I.e. we assume that

$$
E\left[\ln \left(\tilde{\delta}_{\ell}\right)-\ln (\bar{\delta})\right]=0,
$$

even though $\bar{\delta}_{t} \neq \delta_{t}$.

We use the intertemporal Euler equation

$$
E\left[1-\beta\left(\frac{C_{t}}{C_{t+1}}\right)\left((1-\alpha)\left(1-\phi^{-1}\right) \frac{Y_{1+1}}{K_{1+1}}+1\right)\right]=0 .
$$

In the previous section we derived an expression for the level of technology in terms of model parameters, observables and true hours worked. If we simply substitute measured household hours into this expression we obtain a measured level of technology, $\ln \left(X_{t}^{o}\right)$ related to the true level of technology according to $\ln \left(X_{t}^{0}\right)=\ln \left(X_{t}\right)+\varphi_{3} \xi_{3}$.

Since $\xi_{t}$ is mean zero we can use the condition

$$
E v_{t}^{0}=E\left[\ln \left(X_{t}^{0}\right)-\ln \left(X_{t-1}^{o}\right)-\gamma\right]=0 \text {. }
$$

Furthermore, we have

$$
E\left(v_{t}^{0}\right)^{2}=E\left[\left(v_{1}-\varphi_{3} \Delta \xi_{t}\right)^{2}\right]=\sigma_{t}^{2}+2 \varphi_{3}^{2} \sigma_{t}^{2} .
$$

Since we only identify $\ln \left(X_{t}\right)$ up to a constant, we do not estimate the value of $g$, the steady state value of $G_{t}$ relative to $X_{t}$. Instead, we estimate the value of $(g / y)$ the steady state share of government expenditure out of output. This parameter is identified using the moment restriction

$$
E\left[\ln \left(G_{t}\right)-\ln \left(Y_{t}\right)-\ln (g / y)\right]=0 .
$$

Our measure of $\ln \left(G_{i}\right)-\ln \left(X_{i}^{\circ}\right)$ displays a downward trend. Since our model does not capture this feature, we define $g_{i}^{\circ}=\ln \left(G_{i}\right)-\ln \left(X_{i}^{0}\right)-g_{0}-g_{1} t$, in order to obtain a mean zero, trendless process for shocks to government expenditure consistent with our model's specification. We then impose the following restrictions

$$
\begin{array}{r}
E g_{i}^{0}=E\left[\ln \left(G_{t}\right)-\ln \left(X_{i}^{0}\right)-g_{0}-g_{1} t\right]=0 \\
E\left(g_{i}^{0} t / T\right)=E\left[\ln \left(G_{1}\right)-\ln \left(X_{i}^{0}\right)-g_{0}-g_{1} t\right] t / T=0
\end{array}
$$

The measurement error in $X_{i}^{0}$ implies that $g_{i}^{0}=g_{i}-\varphi_{3} \xi_{i}$. Thus we have the moment restrictions

$$
\begin{aligned}
E\left[\left(g_{i}^{\circ}-\rho g_{i-1}^{0}\right) \ln \left(g_{i-1}^{0}\right)\right] & =-\rho \varphi_{3}^{2} \sigma_{\xi}^{2} \\
E\left[\left(g_{i}^{0}-\rho g_{i-1}^{\circ}\right)^{2}\right] & =\left(1+\rho^{2}\right) \varphi_{3}^{2} \sigma_{\xi}^{2}+\sigma_{c}^{2}
\end{aligned}
$$

Finally, since deviations between $K_{t}$ and $\tilde{K}_{\mathbf{l}}$ are transitory, we impose the restriction that the capital-output ratios implied by these two series have the same mean. I.e. we impose the restriction

$$
E\left[\ln \left(K_{t} / Y_{t}\right)-\ln \left(\tilde{K}_{t} / Y_{t}\right)\right]=0
$$


Equations (A.12) and (A.13)-(A.23) are used to identify the 12 elements of $\Psi_{1}$. These equations identify the parameters since our measures of technology, $X_{i}^{\circ}$, and capital $K_{t}$, both depend on $\boldsymbol{\Psi}_{1}$.

As in Christiano and Eichenbaum (1992), we focus on three types of moments as diagnostics for the performance of our model.

i. the standard deviation of a variable of interest, $z_{t}$, denoted $\sigma_{z}$,

ii. the standard deviation of one variable, $s_{t}$, relative to that of another variable, $z_{i}$, denoted $\sigma_{2} / \sigma_{2}$,

iii. the correlation between $s_{t}$ and $z_{t}$, denoted $\rho_{a x}$.

Ignoring means (which are zero for HP filtered data), in order to identify these moments in our data, we use moment restrictions of the form

$$
\begin{array}{r}
E\left[z_{l}^{2}-\sigma_{z}^{2}\right]=0 \\
E\left[s_{l}^{2}-\left(\sigma_{l} / \sigma_{z}\right)^{2} z_{l}^{2}\right]=0 \\
E\left[s_{l} z_{t}-\rho_{l} \sigma_{2} \sigma_{2}\right]=0 .
\end{array}
$$

\section{A.4 GMM Estimation Procedure and Diagnostic Tests}

To define our joint estimator of $\Psi_{1}$ and $\Psi_{2}$ consider the following generic representation of our moment conditions:

$$
E\left[M_{t}\left(\Psi^{0}\right)\right]=0 \forall t \geq 0
$$

where $\Psi^{0}$ is the true value of $\left(\boldsymbol{\Psi}_{1}, \boldsymbol{\Psi}_{2}\right)$. Here $M_{1}$ is a vector valued function of dimension equal to the dimension of $\Psi^{0}$. Let $g_{T}$ denote the vector valued function

$$
g_{T}(\Psi)=\frac{1}{T} \sum_{i=1}^{T} M_{i}(\Psi)
$$

Under the conditions discussed in Hansen (1982), $\Psi^{\circ}$ can be consistently estimated by choosing the value of $\Psi$, say $\Psi_{T}$, that minimizes the quadratic form

$$
J_{T}=T g_{T}(\Psi)^{\prime} S_{T}^{-1} g_{T}(\Psi)
$$

where $S_{T}$ is a consistent estimate of $2 \pi$ times the spectral density matrix of $M_{l}\left(\Psi^{0}\right)$ at frequency zero. For the sake of convenience, we refer to $S_{T}$ as 'the weighting matrix'.

A consistent estimator of the variance-covariance matrix of $\Psi_{T}$ is given by

$$
\operatorname{Var}\left(\Psi_{T}\right)=\frac{1}{T}\left[D_{T}^{\prime} S_{T}^{-1} D_{T}\right]^{-1}
$$

where $D_{T}=\partial g_{T}\left(\Psi_{T}\right) / \partial \Psi^{\prime}$.

Suppose we wish to assess the empirical plausibility of the model's implications for a $q \times 1$ subset of $\Psi_{2}$ which we denote by $\omega$. Let the value of $\omega$ implied by the model, 
given the structural parameters $\Psi_{1}$ be denoted by $\Pi(\Psi)$. Here $\Pi$ denotes the (nonlinear) mapping between the model's structural parameters and the relevant population moments. The value of $\omega$ obtained directly from the data (without imposing the restrictions of the model) is given by $\Gamma \Psi$, where $\Gamma$ is a conformable matrix of zeros and ones that selects the vector $\omega$ from $\Psi_{2}$. Many of the hypotheses we are interested in investigating are of the form

$$
H_{0}: F\left(\Psi^{0}\right)=\Pi\left(\Psi^{0}\right)-\Gamma \Psi^{0}=0
$$

Christiano and Eichenbaum (1992) show that

$$
\operatorname{Var}\left[\boldsymbol{F}\left(\boldsymbol{\Psi}_{T}\right)\right]=\left[\boldsymbol{F}^{\prime}\left(\boldsymbol{\Psi}_{T}\right)\right]\left[\operatorname{Var}\left(\boldsymbol{\Psi}_{T}\right)\right]\left[\boldsymbol{F}^{\prime}\left(\boldsymbol{\Psi}_{T}\right)\right]^{\prime}
$$

and that the test statistic

$$
\mathcal{W}_{T}=F\left(\Psi_{T}\right)^{\prime} \operatorname{Var}\left[F\left(\Psi_{T}\right)\right]^{-1}\left[F\left(\Psi_{T}\right)\right]
$$

is asymptotically distributed as a $\chi^{2}$ random variable with $q$ degrees of freedom.

In exactly identified systems, $\Psi_{T}$ is invariant to the way the weighting matrix $S_{T}$ is estimated. However the covariance matrix of $\Psi_{T}$ and the $W_{T}$ statistic in (A.30) do depend on $S_{T}$. We report results based on Andrewg' (1991) modification of the estimator suggested by Newey and West (1987). We treat this estimator as a benchmark because the results in Burnside and Eichenbaum (1994) suggest that it has attractive small sample properties relative to other widely used alternatives. ${ }^{31}$ Our estimator is of the form:

$$
S_{T}=\frac{T}{T-d} \sum_{j=-(T-1)}^{T-1} k\left(\frac{j}{B_{T}}\right) \hat{\Phi}_{j}
$$

where $d$ is the dimension of $\Psi, T$ is the sample size,

$$
\hat{\Phi}_{j}= \begin{cases}T^{-1} \sum_{t=j+1}^{T} M_{t}\left(\Psi_{T}\right) M_{t-j}\left(\Psi_{T}\right)^{\prime} & \text { for } j \geq 0 \\ T^{-1} \sum_{t=-j+1}^{T} M_{t+j}\left(\Psi_{T}\right) M_{t}\left(\Psi_{T}\right)^{\prime} & \text { for } j<0\end{cases}
$$

and

$$
k_{B}(x)= \begin{cases}1-|x| & \text { for }|x| \leq 1 \\ 0 & \text { otherwise }\end{cases}
$$

Here $(T / T-d)$ is a small sample degrees of freedom adjustment suggested by Andrews (1991), and $B_{T}$ is a scalar that determines the bandwidth of the lag window, $k(\cdot)$. Applying Andrews' (1991) automatic bandwidth selection procedure to our problem yields a value of $B_{T}$ equal to 2.77 .

\footnotetext{
${ }^{31}$ For a more complete discusaion of alternative eatimators for $S_{T}$ see Burnoide and Eichenbaum (1994) or Christiano and den Haan (1993).
} 